DIW BERLIN

Discussion

Papers
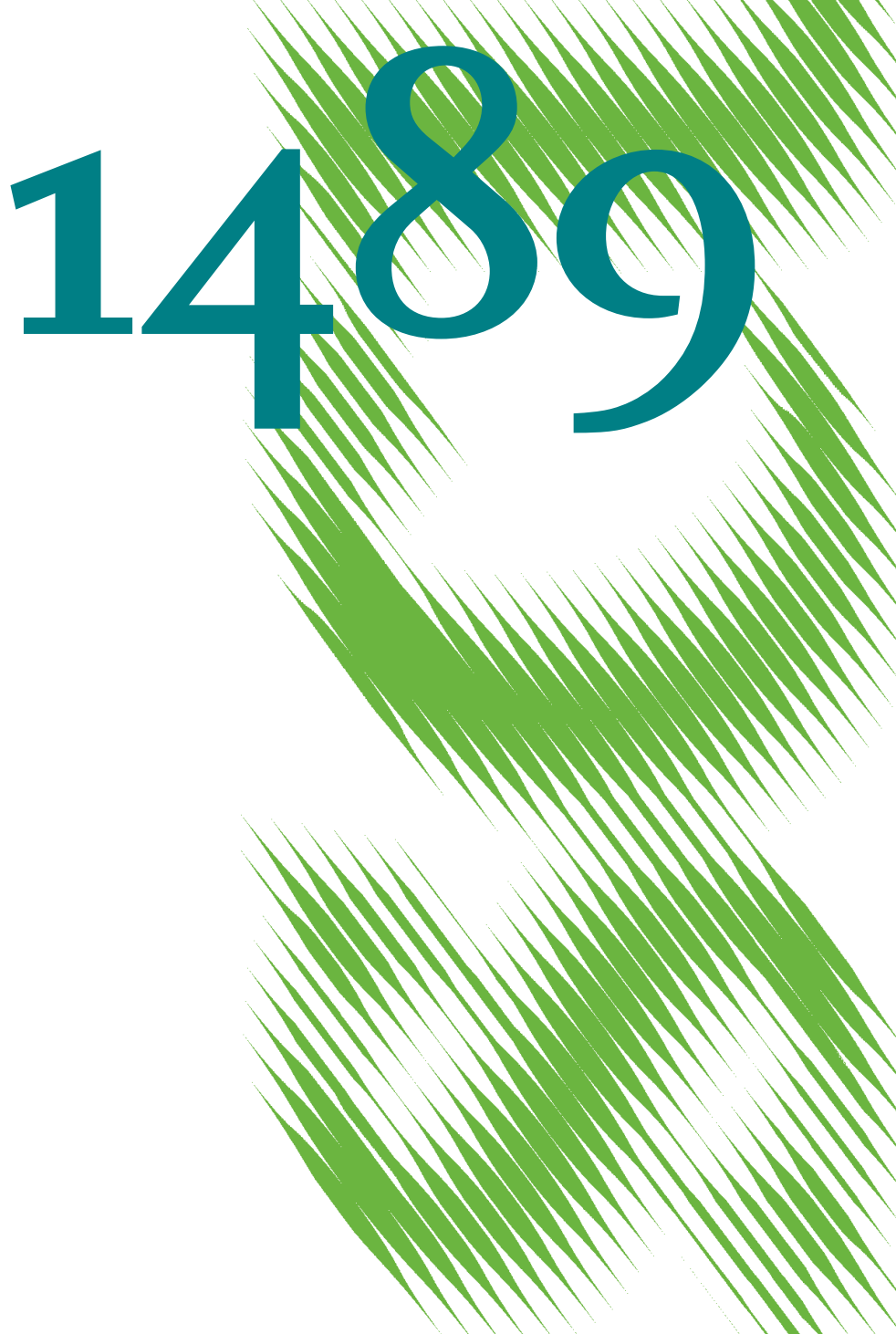

Earnings Responses to Social Security Contributions 
Opinions expressed in this paper are those of the author(s) and do not necessarily reflect views of the institute.

IMPRESSUM

(C) DIW Berlin, 2015

DIW Berlin

German Institute for Economic Research

Mohrenstr. 58

10117 Berlin

Tel. +49 (30) $89789-0$

Fax +49 (30) $89789-200$

http://www.diw.de

ISSN electronic edition 1619-4535

Papers can be downloaded free of charge from the DIW Berlin website:

http://www.diw.de/discussionpapers

Discussion Papers of DIW Berlin are indexed in RePEc and SSRN:

http://ideas.repec.org/s/diw/diwwpp.html

http://www.ssrn.com/link/DIW-Berlin-German-Inst-Econ-Res.html 


\title{
Earnings Responses to Social Security Contributions*
}

\author{
Michael Neumann ${ }^{\dagger}$
}

June 11, 2015

This paper exploits discontinuities induced by earnings caps for social security contributions (SSC) in Germany to analyse the effect of SSC on gross labour earnings. Empirical evidence is based on two complementary approaches utilising two administrative data sets. First, employment responses to SSC at the intensive margin are identified by a modified bunching approach that is applied to kinks in the budget set generated by the earnings caps. Second, I exploit an increase of a regional earnings cap of health and long-term care insurance as a natural experiment. In order to analyse economic incidence a difference-in-differences approach is used to estimate the effects on gross earnings. I find employment responses to be negligible and the burden of SSC to be shared equally between employers and employees. Both results turn out to be robust and are consistent with a competitive labour market model.

Keywords: Social Security Contributions; Tax Incidence; Labour Supply Elasticities; Labour Demand Elasticities; Bunching

JEL: H22; H24; J38

\footnotetext{
* I would like to thank Stuart Adam, Leon Bettendorf, Nicole Bosch, Antoine Bozio, Thomas Breda, Julien Grenet, Peter Haan, Luke Haywood, Holger Lüthen, Kai-Uwe Müller, David Phillips, Barra Roantree and seminar participants at DIW Berlin, IAB Nuremberg, Paris School of Economics, the Berlin Network of Labor Market Research and the EEA Annual Conference 2013 for helpful comments and discussions. This paper has been written as a contribution to the project 'The Impact of Social Security Contributions on Earnings: Evidence from administrative data in France, Germany, the Netherlands and the UK' sponsored by the Deutsche Forschungsgemeinschaft. $\dagger$ German Institute for Economic Research (DIW Berlin), Mohrenstr. 58, D-10117 Berlin, Germany, Tel.: +49 3089789 353, Fax: +49 3089789 114, E-mail: mneumann@diw.de
} 


\section{Introduction}

In most industrialised countries social security contributions (SSC) represent a large share of total taxation. In 2010, SSC amounted to $9.1 \%$ of GDP and $26.4 \%$ of total tax revenues in OECD countries (OECD 2015). Since they are (usually) nominally shared between employers and employees it is hardly surprising that SSC are often claimed to be detrimental to employment and economic growth (see for example OECD (1994) and Prescott (2004)). Some governments seem to have followed this reasoning by implementing reforms to decrease SSC or switch from SSC to other means of revenue generation (Melguizo and Gonzalez-Paramo 2013). During 2011 and 2012, the US decreased the employees' share of payroll taxes by two percentage points (pp.) in order to boost consumption. Many countries including Germany, Denmark and France increased the value added tax in order to finance a decrease in SSC. Additionally, there seems to be a tendency to shift some legal burden of SSC from employers to employees. Germany, for example, abolished the equal sharing of SSC in 2005. To understand the effect of such reforms on disposable income, employment and welfare, the elasticities of labour supply and demand with respect to SSC as well as economic incidence are crucial.

Based on two large administrative data sets this study analyses these parameters for employees in the upper part of the earnings distribution. Identification makes use of the fact that SSC rates in Germany (as in many other countries) only apply up to certain thresholds of earnings, in the following called (earnings) caps. Firstly, behavioural responses are studied within a modified bunching approach (Saez (2010) and Chetty, Friedman, Olsen and Pistaferri (2011)). Secondly, economic incidence is estimated within a quasi-experimental approach as similarly done by Gruber (1994), Gruber (1997) and Saez, Matsaganis and Tsakloglou (2012).

More precisely, the discontinuous drop of the marginal SSC rate at an earnings cap generates a kink in the budget set. The modified bunching approach exploits the information that the size of a potential dip in the earnings distribution at such a kink contains about intensive margin employment responses to a change in SSC. Eight earnings caps between 1998 and 2004 are analysed with the drop of the marginal SSC rate varying between 15 and $27 \mathrm{pp}$. 
Economic incidence is estimated by exploiting exogenous variation of SSC over time generated by a considerable increase of a regional earnings cap of health and long-term care insurance in 2001. I estimate difference-in-differences models using employees with earnings above the earnings cap as treatment group and employees with earnings somewhat below as control group. The amount of hours worked and respectively hourly wages are not observed in the administrative data used here. I, therefore, follow the literature (Anderson and Meyer (2000), Bennmarker, Mellander and Öckert (2009) and Saez et al. (2012)) and identify economic incidence by the reaction of yearly gross earnings ${ }^{1}$ under the assumption of no employment responses. In the present application, however, this usually restrictive assumption can be credibly defended based on two arguments. First, a group of employees is only exposed to a change of the average SSC rate. Second, the preceding analysis of behavioural responses to earnings caps lends additional support to the assumption.

I find employment responses at the intensive margin to be negligible. Further, according to my results economic and legal incidence coincide implying that employees and employers share the burden of SSC roughly in equal parts. Taken together, this suggests that labour supply and demand elasticities both are very low. Considering that earnings caps naturally affect rather high-skilled employees, this result is consistent with the previous literature. The findings on economic incidence and behavioural responses are consistent with a standard competitive labour market model where economic incidence is determined by the ratio of labour demand and supply elasticities.

My contribution to the literature is to provide fresh evidence on behavioural responses to SSC as well as economic incidence. Previous evidence on behavioural responses to SSC is rather rare (Saez et al. 2012) which is astonishing because the specific features of SSC in comparison to income taxes require to analyse their effects separately. I translate the bunching method by Saez (2010) to 'upward' kinks' in the budget set. This avoids some of the major problems responsible for the insufficient evidence. First,

1 Throughout the text, gross earnings include employees' SSC but are net of employers' SSC. Net earnings are gross earnings minus employers' and employees' SSC and labour costs are gross earnings plus employers' SSC.

2 An upward kink in a gross-net earnings diagram is generated by a discontinuous drop in the marginal tax rate at a certain threshold. By contrast, Saez (2010) analyses downward kinks generated by an increase in the marginal tax rate. 
it does not depend on the existence of an exploitable policy reform. Second, it does not require information on hours of work. I can, therefore, use large administrative data sets that frequently do not include the exact amount of working hours. Third, while most existing evidence is limited to short-term effects, I argue that in the present setting the bunching method allows for estimating long-term responses.

Although there is substantially more empirical work on economic incidence of SSC, previous results are mixed. One potential reason is that economic incidence of SSC seems to crucially depend on the institutional setting like the centralisation of the wage bargaining process (Alesina and Perotti (1997) and Daveri and Tabellini (2000)). Yet, hardly any evidence is available for Continental European countries which mostly feature an intermediate degree of centralisation of the wage bargaining process. This study fills that gap by providing evidence for high-skilled employees in Germany.

Further, increasing the earnings cap for SSC is interesting in itself as it constitutes a feasible policy for many countries to increase revenues or to shift the burden to employees in the upper part of the earnings distribution. In the UK, for example, the earnings cap for employers' SSC was abolished in 1985 as were most earnings caps for SSC in France in the 1980s. This study contributes to the controversial discussion of welfare effects and efficiency of an increase of an earnings cap for SSC (as briefly summarized by Liebman and Saez (2006)).

The paper is organised as follows. Section 2 discusses the existing literature. Section 3 presents the German social security system. Section 4 reviews the evidence on behavioural responses based on cross-sectional variation in SSC. The evidence on economic incidence based on the increase of the earnings cap in 2001 is discussed in section 5. Section 6 discusses the findings of both approaches and section 7 concludes.

\section{Literature}

This study relates to the large strand of literature on the effects of taxes on labour market outcomes. Blundell and Macurdy (1999) as well as Meghir and Phillips (2010) survey the vast evidence on income taxation. The specific characteristics of SSC have given rise to an own branch of empirical literature. There is a much larger body of 
research on economic incidence for SSC than for personal income tax, probably because labour taxes formally paid by employers are considered to be more prone to burden shifting than taxes paid by employees. In contrast, evidence on behavioral responses or employment effects to $\mathrm{SSC}$ is rather rare.

The early work on economic incidence was mainly based on cross-country national account data (see for example OECD (1990)) and usually found that labour taxes are completely shifted to workers. However, more recent multi-country studies draw a more differentiated picture and conclude that shifting to wages seems to be an inverse U-shaped function of the degree of centralisation of wage bargaining (Alesina and Perotti (1997) and Daveri and Tabellini (2000)) and increases with the link between contributions and benefits (Ooghe, Schokkaert and Flechet (2003)).

Most empirical studies are based on individual data. With respect to methodology, these studies can roughly be classified into two groups. First, some studies exploit variation in SSC rates over time or cross-sectional units and frequently find that increases in payroll tax rates are just partly shifted to wages (see for example Holmlund (1983) for Sweden, Hamermesh (1979) and Neubig (1981) for the US).

Second, policy reforms are exploited as natural experiments in order to estimate both, economic incidence of SSC and effects on employment. In an influential paper, Gruber (1994) analyse the effects of the introduction of mandated maternity benefits in the US on gross hourly wage rates and employment with a difference-in-differences-indifferences approach. Based on survey data he finds substantial shifting to wages and no impact on overall labour input. Since then, a large amount of quasi-experimental studies have been conducted for many different countries. Identification is based on variation between, among others, firms (Anderson and Meyer (2000) for the US, Gruber (1997) for Chile), industries (Bell, Jones and Thomas (2002) for the UK), age (Skedinger (2014) for Sweden) and regions (Bennmarker et al. (2009) for Sweden, Korkeamäki and Uusitalo (2009) for Finland, Baicker and Chandra (2006) for the US). The results are very mixed which is reflected in a meta-study based on 52 empirical papers (Melguizo and Gonzalez-Paramo 2013). On average $66 \%$ of labour taxes are estimated to be borne by employees with a standard deviation of $51 \mathrm{pp}$. Some of these studies also analyse the impact of SSC on employment but rarely find statistically and 
economically significant effects.

Only few studies exploit the discontinuity induced by an earnings cap for SSC. Similar to section 5 of this study, Lang (2003) and Liang, Kubik and Engelhardt (2004) analyse significant increases of the earnings cap of the American Federal Insurance Contribution Act (FICA) ${ }^{3}$ between 1968 and 1979. While Lang (2003) finds that earnings of treated individuals rose consistently stronger in years the cap increased, Liang et al. (2004) conclude that gross hourly wages were not significantly affected. Further, the latter study finds a small negative employment effect at the intensive margin. Saez et al. (2012) evaluate a Greek reform which created parallel regimes by increasing the earnings cap for SSC for all employees who started working on or after 1993. They, therefore, estimate credible long-term effects which most other studies could not provide and find that economic and legal incidence coincide as well as that labour supply effects are negligible.

A recent strand of literature initiated by Saez (2010) and Chetty et al. (2011) exploits cross-sectional variation in tax rates to analyse behavioural responses. This so-called bunching approach does not depend on exogenous policy reforms. Under some additional assumptions it facilitates the estimation of long-term responses. This is a major advantage over reform evaluations which analyse the response to a change in incentives and, therefore, usually estimate short- or medium-run effects. Identification of the aforementioned studies is based on discontinuous jumps in the marginal (income) tax rate. Discontinuous drops as they appear at earnings caps for SSC are not at all or only informally covered. In section $4 \mathrm{I}$, therefore, modify the bunching method to analyse behavioural responses to the German earnings caps for SSC.

\section{Institutions}

This study focuses on the impact of SSC on gross earnings in Germany. The German social security system consists of pension, health, unemployment, and long-term care insurance. In comparison to personal income taxes, SSC in Germany and many other countries have some specific features which are crucial for economic incidence and be-

3 Similar to the caps analysed in this study, the marginal payroll tax rate drops to zero at the earnings cap of FICA. 
havioural responses.

First, they are financed by flat contribution rates with daily gross earnings as tax base. Over the last twenty years the total SSC rate varied around $40 \%$ of gross earnings with pension (around $20 \%$ ) and health insurance (around $14 \%$ ) as the most important branches (figure 1). The contribution rate to unemployment insurance decreased from $6.5 \%$ before 2007 to $3 \%$ in 2012. Apart from that the respective SSC rates did not change substantially.

Figure 1: Development of SSC rates over time

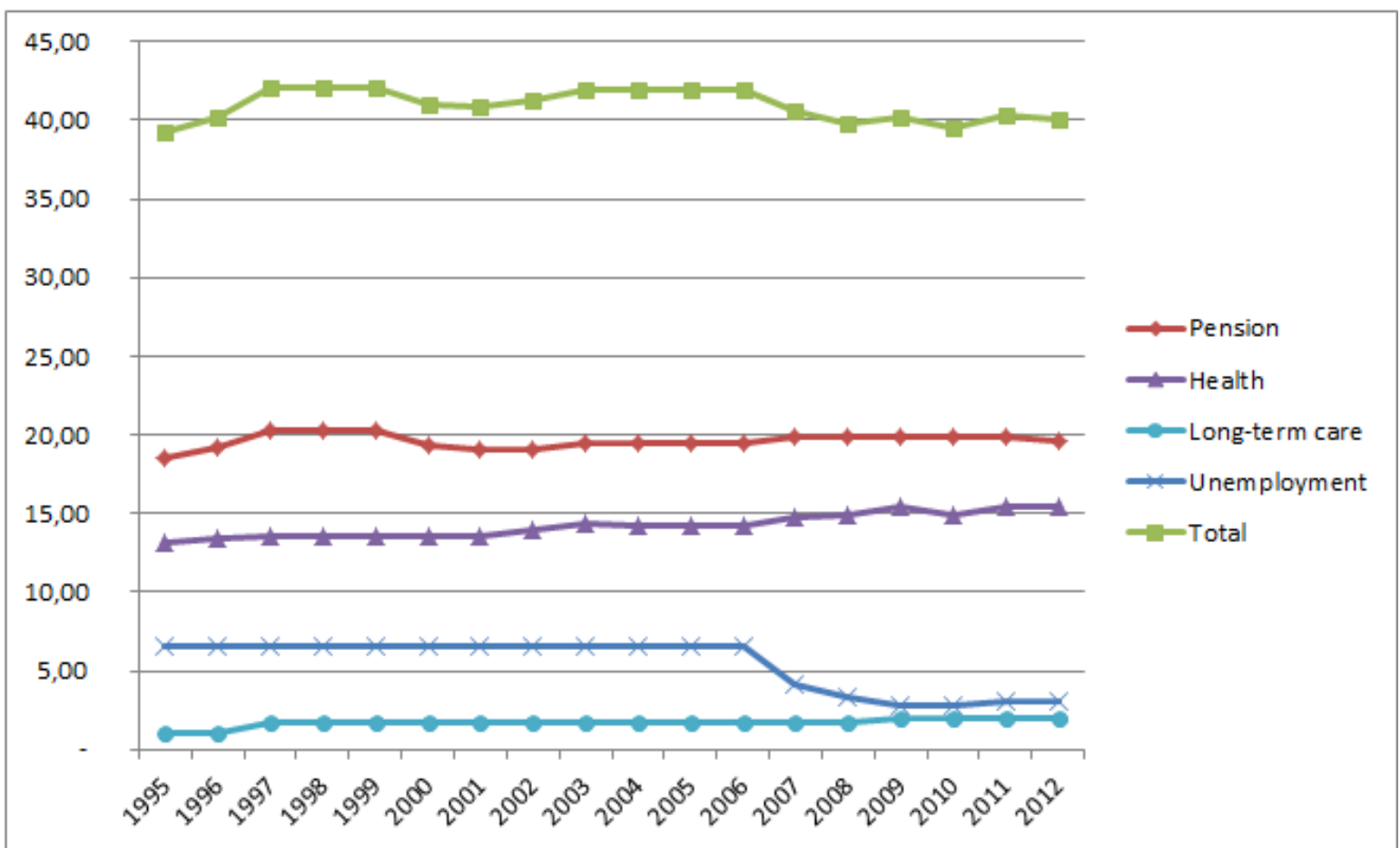

Source: http://www.statistik.baden-wuerttemberg.de

The additional fee for childless employees, introduced in 2005, is omitted. The change of SSC which came into effect in July 2005 are considered as of 2006. Until 2006 SSC rates for health insurance varied between health insurance companies and the given numbers are averages. In 2001, for example, it varied between $11.0 \%$ and $14.9 \%$ (Grabka 2004).

Second, the burden is statutorily shared between employers and employees. Until 2004 this split was equal. Since 2005, 0.9 pp. (plus 0.25 pp. for childless employees) are exclusively paid by employees 4 . As of 2009, providers of public health care may charge so-called 'auxiliary contributions'. In 2011 the employers' SSC rate was fixed such that future increases are only born by employees. However, as these changes have been rather gradual, the present study does not use them as a source of identification.

4 There are specific rules for Saxony. 
Third and most important for this study, marginal SSC rates only apply up to certain thresholds of earnings, in the following called (earnings) caps. There is a common cap for pension $5^{5}$ and unemployment insurance that varies between East and West Germany (figure 2). A second, lower cap is defined for health and long-term care insurance ${ }^{6}$. Until 2000 it was also different for East and West Germany and until 2002 it was 3/4 of the cap of pension insurance. All caps are adjusted yearly according to the average change in wage earnings. However, there have only been very few substantial changes. There is a strong increase of the East German health earnings cap in 2001 when it is harmonised with the cap in West Germany. I exploit this jump to estimate economic incidence of SSC (section 5). Comparable jumps in the caps of pension insurance in 2003 cannot be utilised due to data limitations. In addition the cross-sectional variation in SSC generated by all four German earnings caps is exploited to estimate behavioural responses to $\mathrm{SSC}$ (section 4).

Fourth, SSC differ from other taxes as they might be directly linked to benefits. In Germany, individual pension and unemployment benefits are a function of earnings. For earnings above the cap, benefits solely depends on the cap. However, there is no direct link between benefits and the cap of health insurance 7 .

\section{Behavioural Responses}

This section analyses behavioural responses to SSC by exploiting the cross-sectional variation in SSC rates. To do that, I translate the bunching approach by Saez (2010) and Chetty et al. (2011) to upward kinks in the budget set where the marginal SSC rate drops discontinuously ${ }^{8}$. It is shown that a potential gap or dip in the earnings distribution at such a kink contains information about intensive margin employment responses to a change in SSC. However, analysing eight German earnings caps between 1998 and 2004, no gaps or dips are found (section 4.4). Assuming that economic inci-

5 There is a special earnings cap for miners' pension insurance. However, as it is usually higher than the standard one, it does not pose a problem for the analysis.

${ }^{6}$ For the sake of readability I speak in the following of earnings caps of pension and health insurance instead of also mentioning unemployment and long-term care insurance.

7 Compensation in case of an illness lasting over 6 weeks is an exception.

8 By contrast, Saez (2010) analyses downward kinks generated by an increase in the marginal tax rate. 
Figure 2: Development of earnings caps over time

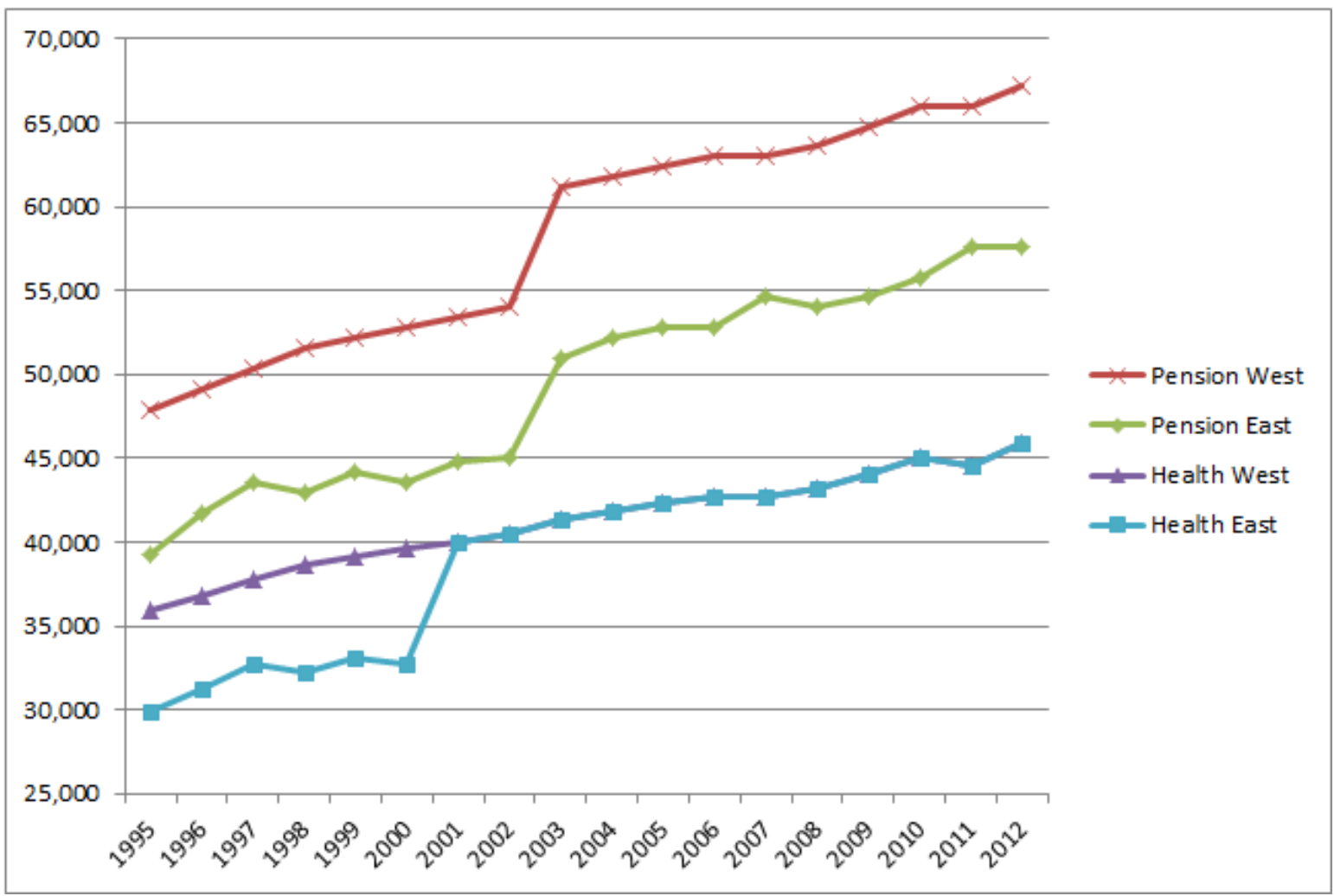

Source: http://www.statistik.baden-wuerttemberg.de

The vertical axis pertains to yearly gross earnings.

dence is entirely with employees, this implies that for employees in the upper part of the earnings distribution the compensated elasticity of labour supply is low. Although this assumption on economic incidence is common in the literature on labour supply, there are arguments against its validity. First, in contrast to income taxation, legal incidence of SSC is shared between employees and employers. Second, previous studies for other countries (section 2) and the findings of this study (section 5) lend support to the claim that employers and employees share the economic burden of SSC. While I maintain the standard assumption on economic incidence throughout this section, the implications of relaxing it are discussed in section 6 .

Finally, the bunching approach is restricted to analyse employment responses at the intensive margin. This study does not present any evidence on participation effects. However, as the German earnings caps appear in the upper part of the earnings distribution, strong employment responses at the extensive margin are not likely. 


\subsection{Theory}

Following Saez (2010), assume that preferences of employees can be represented by a quasi-concave utility function $u(c, y)$ which depends negatively on gross earnings $y$ and positively on consumption $q^{9}$. Let ability $n$ be smoothly distributed over the population. In such a setting, downward kinks in the budget set (generated by a jump in the marginal tax rate) might create the incentive to locate at these kinks. Saez (2010) shows that the observed extent of bunching can be used to estimate the structural compensated labour supply elasticity. By contrast, an earnings cap at $\bar{y}$ where the marginal SSC rate drops from $t_{0}$ to $t_{1}$ generates the piecewise linear budget set (1) with an upward kink at $\bar{y}$ and $R$ denoting non-wage income.

$$
c= \begin{cases}\left(1-t_{0}\right) y+R & \forall y \leq \bar{y} \\ \left(1-t_{0}\right) \bar{y}+\left(1-t_{1}\right)(y-\bar{y})+R & \forall y>\bar{y}\end{cases}
$$

Building on the assumption of convex preferences it can be shown that there always exists an interval around an upward kink which does not contain a global maximum (Burtless and Hausman 1978). If the labour supply elasticity is homogeneous this implies a gap in the earnings distribution (Saez 2010). Intuitively, employees extend their working hours until the utility of an additional hour of work is offset by the hour of leisure lost. Therefore, employees who locate closely ${ }^{10}$ to the right of the hypothetical kink in a linear tax system would extend their labour supply if an upward kink is introduced as the marginal utility of an additional hour of work increases discontinuously. The same is true for employees who locate close enough to the left of the hypothetical kink in a linear tax system such that the utility gain due to the additional lowly taxed hours beyond the kink at least offsets the utility loss due to the additional highly taxed hours up to the kink.

Assuming that $u(c, y)$ satisfies the single-crossing property there is an unique ability level $\tilde{n}$ above (below) which employees prefer locating above (below) the kink. This is shown exemplarily by means of a quasi-linear and iso-elastic utility function in Appendix

9 Appendix A.1 specifies a quasi-linear and iso-elastic utility function to illustrate the general relationships derived in this section.

${ }^{10}$ Such that income effects are negligible. 
A.1. Let $\tilde{y}_{0}<\bar{y}$ denote the optimal gross earnings of an individual with ability $\tilde{n}$ in the absence of a kink and $\tilde{y}_{1}>\bar{y}$ if there is an upward kink at $\bar{y}$. The compensated ${ }^{11}$ elasticity of labour supply, $e$, is then defined as

$$
e=\frac{\tilde{y}_{0}-\tilde{y}_{1}}{\tilde{y}_{0}} \frac{1-t_{0}}{t_{0}-t_{1}}=\frac{d \tilde{y}}{\tilde{y}_{0}} \frac{1-t_{0}}{d t}
$$

While $\frac{1-t_{0}}{d t}$ is known by the tax system, $\frac{d \tilde{y}}{\tilde{y}_{0}}$ has to be estimated in order to infer $e$. This can be done by measuring the position and extent of the arising gap in the earnings distribution around $\bar{y}$ which will cover all earnings between $\tilde{y}_{0}$ and $\tilde{y}_{1}=\tilde{y}_{0}+\Delta \tilde{y}_{0}$. As it is based on individuals who would locate close to the cap in the counterfactual situation this estimator of $e$ is very local.

However, if the elasticity is heterogeneous (and zero for at least some employees), an upward kink will result in a dip rather than a gap because $d \tilde{y}$ varies over individuals. Analogous to the bunching mass exploited in analyses of downward kinks (Saez 2010), the missing mass $B$ relative to the density of counterfactual earnings, $h_{0}($.$) , can be used$ to approximate the average earnings response:

$$
\begin{aligned}
B & =\iint_{y_{0}}^{y_{0}+\Delta y(e)} h_{0}(y, e) d y d e \\
& \approx \int d y(e) \overline{h_{0}(y, e)} d e \\
& =E_{e}[d y] \overline{h_{0}(y)}
\end{aligned}
$$

$\overline{h_{0}(.)}$ denotes the average counterfactual density in the area of the potential dip. In equation $(2), \overline{h_{0}(.)}$ is assumed to be independent from $e$ which is justified if the distribution is not very steep around $\bar{y}$. By contrast to the analysis of a downward kink, $\tilde{y}_{0}$ varies over individuals. Therefore, the average relative earnings response cannot be calculated directly. Instead, specifying a utility function allows expressing $\tilde{y}$ as a function of the elasticity. Based on a quasi-linear and iso-elastic utility function equation (12) in Appendix A.1, then, constitutes a direct relationship between $B, e$ and the parameters of the tax system.

${ }^{11}$ This is only valid for small tax changes as for large tax changes income effects might matter (Saez 2010). 


\subsection{Empirical Methodology}

The empirical task is to detect a potential gap or dip in the gross earnings distribution around the earnings cap. To do that, the observed distribution is compared to an estimated distribution which approximate the counterfactual situation of a linear SSC schedule. Following Chetty et al. (2011) the counterfactual distribution is estimated by a polynomial of degree $P$ fitted to the number of observations $\left(C_{j}\right)$ in earnings bins. Bin $j$ is defined by its midpoint $Y_{j} €$ and its bin size $k €$. Earnings bins within the interval $(\bar{y}-Q, \bar{y}+Q)$ are assumed to be affected by a potential dip and are, therefore, excluded from the estimation of the counterfactual distribution.

$$
C_{j}=\sum_{p=0}^{P} \beta_{p} Y_{j}^{p}+\sum_{i=-Q}^{Q} \gamma_{i} \mathbf{1}\left[Y_{j}=i\right]+\epsilon_{j}
$$

The counterfactual earnings distribution is $\hat{C}_{j}=\hat{\beta}_{p} Y_{j}^{p}$ as estimated by equation $\sqrt[3]{12}$ Missing mass $B$, then, is the difference between the counterfactual and empirical earnings distributions within the interval $(\bar{y}-Q, \bar{y}+Q)$. In the following, the outlined approach is applied to the earnings caps of pension and health insurance in West and East Germany.

\subsection{Data}

The estimation is based on the Wage and Income Tax Statistics $\left(\right.$ FAST) ${ }^{13}$ which is a representative ten percent sample of households subject to German income tax (3.5 million observations). Due to this relatively large sample size FAST is particularly suitable for the semi-parametric bunching approach. Labour earnings are observed as uncapped yearly gross earnings without information about the amount of hours or months of work. This is sufficient for the purpose of this study because, first, the tax base of SSC is daily gross earnings and, second, earnings of jobs exempted from $\mathrm{SSC}$ are not included in this measure as the lower exemption level also applies to

${ }^{12} \overline{\hat{C}_{j}}$ is not an estimate of the true counterfactual earnings distribution in the absence of a kink. The reason is that all employees with counterfactual earnings above the cap have an incentive to respond to an introduction of the kink. Assuming that the substitution effect dominates, the observed density might, therefore, be less concentrated and shifted to the right.

${ }^{13}$ The German name is Faktisch anonymisierten Daten aus der Lohn- und Einkommensteuerstatistik. 
income tax. Self-employed and civil servants are excluded from the sample. Although FAST is provided every three years I restrict the analysis to two years due to practical considerations. I analyse the 1998 wave because the earnings caps have not changed considerably in the preceding years and the 2004 wave in order to include a year after the decoupling of the earnings cap of health insurance and the threshold for compulsory public health insurance in 2003 (see Appendix B.1). As I differentiate the analysis by East and West Germany as well as by health and pension insurance, eight kinks are analysed in total.

\subsection{Results}

$\hat{B}$ is the estimated amount of missing employees normalized by the average counterfactual density in the excluded range. $\sigma_{\hat{B}}$ denotes the corresponding standard errors, $N$ the amount of individuals underlying the estimation. Graphs of the actual and counterfactual earnings distributions can be found in Appendix A.2. The basic specification is based on polynomials of degree seven and a bin size of $100 € /$ year. An earnings range of $3000 € /$ year below and above the kink is excluded. The latter is chosen by means of a simulation exercise described in Appendix A.3. I do not find a statistically significant deviation between counterfactual and empirical earnings distribution at any of the eight kinks (table 1). This implies that there are neither gaps nor dips. The results turn out to be very robust to successively varying the degree of the polynomial, the bin size and the exclusion range. The only exceptions are the caps of health insurance when the degree of the polynomial is decreased to five (table 1).

As discussed above, equation 12 in Appendix A.1 allows transferring $\hat{B}$ into an estimate of the labour supply elasticity, $e$, based on a quasi-linear and iso-elastic utility function. The point estimate of pension insurance in West Germany in $1998(\hat{B}=-1.49)$ implies $\hat{e} \approx 0.01$. With an upper bound of the confidence interval of 0.03 , the estimate is quite precise. By contrast, East German estimates are much less precise, arguably because of the much smaller sample size. The point estimate $\hat{B}=-2.26$ translates to $\hat{e} \approx 0.02$ with an upper bound of the confidence interval of 0.07 . For most other earnings caps the estimated missing mass is much smaller or even negative (i.e. $\hat{B}>0$ ) implying a smaller $\hat{e}$. According to these estimates, the compensated labour supply 
Table 1: Bunching analysis of employment responses

\begin{tabular}{|c|c|c|c|c|c|c|c|c|c|c|c|c|}
\hline \multirow[b]{3}{*}{ Specification } & \multicolumn{6}{|c|}{1998} & \multicolumn{6}{|c|}{2004} \\
\hline & \multicolumn{3}{|c|}{ Pension } & \multicolumn{3}{|c|}{ Health } & \multicolumn{3}{|c|}{ Pension } & \multicolumn{3}{|c|}{ Health } \\
\hline & $\hat{B}$ & $\sigma_{\hat{B}}$ & $\frac{N}{1000}$ & $\hat{B}$ & $\sigma_{\hat{B}}$ & $\frac{N}{1000}$ & $\hat{B}$ & $\sigma_{\hat{B}}$ & $\frac{N}{1000}$ & $\hat{B}$ & $\sigma_{\hat{B}}$ & $\frac{N}{1000}$ \\
\hline & \multicolumn{12}{|c|}{ West } \\
\hline Basic & -1.49 & 1.60 & 224 & 1.82 & 1.07 & 338 & 1.71 & 1.06 & 257 & 1.06 & 0.62 & 474 \\
\hline Degree 5 & -1.17 & 1.32 & 224 & -5.17 & 1.00 & 338 & 0.21 & 0.89 & 257 & -2.13 & 0.59 & 474 \\
\hline Bin Size 300 & -0.72 & 0.49 & 223 & 0.69 & 0.39 & 336 & 0.82 & 0.37 & 254 & 0.41 & 0.21 & 470 \\
\hline \multirow[t]{2}{*}{ Excluded 20} & -0.88 & 1.07 & 235 & 0.82 & 0.76 & 357 & 1.44 & 0.72 & 271 & 1.35 & 0.44 & 498 \\
\hline & \multicolumn{12}{|c|}{ East } \\
\hline Basic & -2.26 & 3.15 & 173 & -0.59 & 1.90 & 310 & -1.02 & 2.56 & 168 & 1.84 & 2.01 & 239 \\
\hline Degree 5 & 4.98 & 3.13 & 173 & -7.57 & 1.52 & 310 & -0.60 & 2.24 & 168 & 2.09 & 1.80 & 239 \\
\hline Bin Size 300 & -0.47 & 1.04 & 171 & -0.44 & 0.57 & 307 & -0.34 & 0.88 & 166 & 0.80 & 0.69 & 236 \\
\hline Excluded 20 & -3.30 & 2.10 & 183 & -0.24 & 1.40 & 328 & -3.59 & 1.70 & 178 & 2.05 & 1.44 & 252 \\
\hline
\end{tabular}

elasticity with respect to SSC (of employees with earnings close to the respective caps) seems to be zero or at least very low.

An alternative explanation for such a small missing mass are frictions like search and adjustment costs which might exceed the utility gains of behavioural responses (Chetty et al. 2011). Based on the quasi-linear and iso-elastic utility function used above I simulate an employee's utility gain (expressed in yearly net earnings) of responding optimally to the German earnings caps (Appendix A.3). For an individual who would locate exactly at the earnings cap in the absence of a kink the utility increases between almost $300 €$ for an elasticity of 0.5 and the West German earnings cap of pension insurance to $16 €$ for an elasticity of 0.1 and the earnings cap of health insurance. Although potential costs of locating optimally are difficult to assess, these rather small gains lend support to the friction story. However, two arguments are to the contrary. First, some of the analysed earnings caps have not been considerably changed for many years which arguably decreases adjustment costs and increases salience. Second, relaxing the assumption that economic incidence is fully with employees implies that employers and employees have the same incentives which might further reduce adjustment costs (section 6).

Both arguments are also in favour of interpreting the results as long-run effects. As the German earnings caps are quite salient and sufficiently long-lasting, employees and 
employers can directly incorporate the earnings cap into wage negotiations. In contrast to reform evaluations which analyse the response to a change in incentives, the bunching approach in the present setting, therefore, facilitates the estimation of long-term effects.

\section{Economic Incidence}

Besides potential responses in working hours to a variation of SSC, changes in the wage rate are another margin of adjustment for gross earnings. As in most labour supply analyses, I assume economic incidence to be entirely with employees in the previous section. According to this assumption a raise of SSC implies that the hourly gross wage rate decreases because SSC are shared between employers and employees. The additional burden is, thus, shifted to employees. Alternatively, if economic coincided with legal incidence, the gross wage rate would be unaffected ${ }^{14}$. Should economic incidence fall entirely to employers, the gross wage rate would increase.

I exploit variation of SSC over time induced by a substantial increase of the East German earnings cap of health insurance to analyse economic incidence. Similar to Gruber (1994) and Saez et al. (2012) the reform is analysed as a quasi-experiment by a difference-in-differences approach.

\subsection{The Reform in 2001}

By January 2001 15 the East German earnings cap of health insurance was adjusted to the West German level (figure 2, section 3). This implied an increase from 32,672 € in 2000 to $40,034 €$ in 2001 or $22.5 \%$. Employees earning less than the pre-reform cap are not affected by the reform. For employees earning between the pre- and post-reform cap, the additional liability increased by their gross earnings (figure 3). Employees earning more than the post-reform cap are exposed to the maximum increase of $1125 €$ /year for employees and employers combined equaling $2.8 \%$ of the earnings cap. Employees with earnings between the pre- and post-reform caps additionally experienced an increase of the marginal SSC rate by $15.3 \mathrm{pp}$. The reform did not affect the marginal SSC rate of

\footnotetext{
${ }^{14}$ This abstracts from a potential effect on effort.
}

15 The reform was announced in December 1999. 
those employees earning more than the post-reform cap.

Figure 3: Total SSC by yearly gross earnings in 2000 and 2001

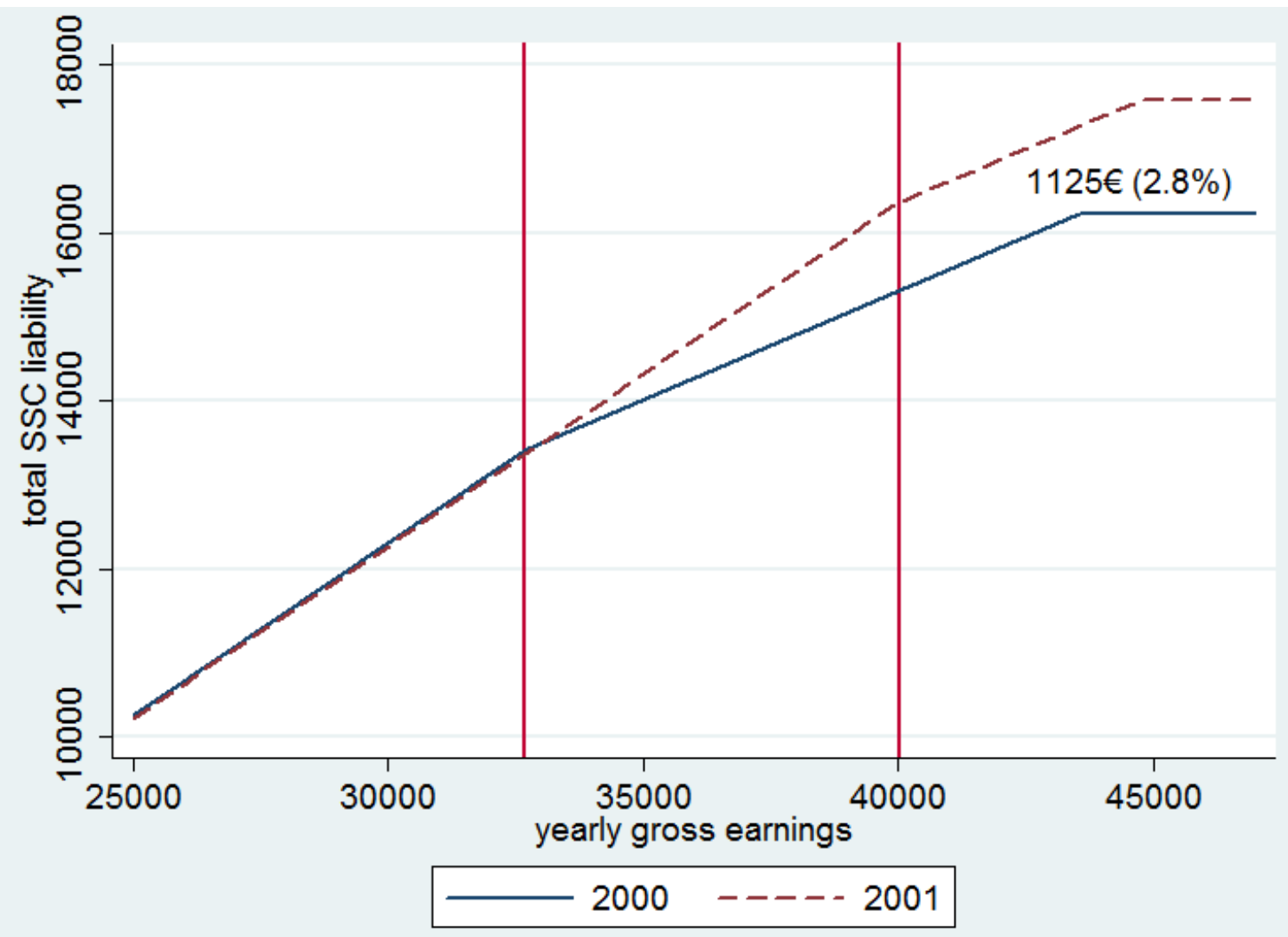

Source: own calculations

Notes: The solid (dashed) curve depicts total SSC by gross earnings in 2000 (2001), before (after) the reform. The difference between both curves is the treatment due to the reform which increased the earnings cap for SSC from the left reference line to the right.

At the time of the reform, the earnings cap for SSC coincided with the threshold above which most employees are allowed to leave mandatory public health insurance and opt for private health insurance. Therefore, employees affected by the reform might have been privately insured before the reform. However, as employers' SSC are capped at the same maximum value in private as well as public health insurance, their treatment due to the reform is comparable in most cases (see Appendix B.1 for a more detailed description of the private health insurance system in Germany and the implications for the reform evaluation). By contrast, the effect of the reform for privately insured employees (i.e. the actual change in their SSC share) cannot be quantified exactly.

Another potential confounding factor is an income tax reform which decreased the income tax rate in 2001. However, as this applied similarly for the control and treatment 
group it does not affect identification in the difference-in-differences approach.

\subsection{Data}

The evaluation of the reform in 2001 is based on the Sample of Integrated Labour Market Biographies (SIAB) ${ }^{16}$ which is a representative two percent sample of all individuals for whom an employer's record to the social security system exist. For the about 1.6 million employees in the sample information on their entire employment history is available, among others yearly gross earnings. The SIAB is particularly suited for the analysis of SSC variation over time for several reasons. First, the panel structure allows to calculate yearly earnings changes of individuals. Second, the information about earnings is very accurate due to the administrative character of the data. Third, as the earnings cap applies to the sum of all labour earnings ${ }^{17}$, observing parallel employment spells is essential. Fourth, the sample size is comparatively large. Fifth, most factors important for wage dynamics are observed. These include age, sex, occupation and education at the individual level. Labour market experience and tenure within an establishment can be derived. Industry sector, establishment size and wage structure are especially noteworthy among establishment level characteristics. The regional unemployment rate can be matched based on the district of workplace.

The earnings information of the SIAB has two major drawbacks, though. First, working time is only differentiated between full- and part-time employment; as in many administrative data sets the exact amount of hours worked and hourly wages are not observed. Second, gross earnings are capped at the earnings cap of pension insurance. The imputation procedures proposed in the literature (see for example Büttner and Rässler (2008)) would not solve the problem here because observed individual earnings changes are crucial for identification. Therefore, I only focus on the increase of the earnings cap of health insurance.

The sample is restricted to full-time employees between 18 and 62 years. Spells with daily gross earnings below three euros and one-time payments are excluded. If an individual has two parallel full-time jobs or two parallel employment spells in the same

\footnotetext{
${ }^{16}$ The German name is "Stichprobe der Integrierten Arbeitsmarktbiografien" (SIAB). See Dorner, König and Seth (2011) for a detailed description of the data.

${ }^{17}$ Plus earnings from most pensions which are not observed.
} 
firm, I exclude the employment spell with lower earnings. The quality of the education variable is inferior to most other variables because this information is not necessary for the administrative process (Dorner et al. 2011). I, therefore, use the first imputation procedure proposed by Fitzenberger, Osikominu and Völter (2006) which is shown to perform best (Wichert and Wilke 2012).

\subsection{Methodology}

The reform is evaluated within a difference-in-differences framework. Employees within a certain quantile of the earnings distribution above the earnings cap form the treatment and employees within a certain quantile below the control group. Since the wage rate is not observed, first differences in gross labour earnings serve as dependent variable as commonly done in the literature (Anderson and Meyer (2000), Bennmarker et al. (2009) and Saez et al. (2012)). Drawing conclusions about economic incidence, therefore, requires the assumption that the reform does not affect the amount of hours worked. Given that leisure is a normal good, the reform, however, creates incentives for both, employers and employees. In response to an increase in marginal SSC rates employees (employers) might want to decrease hours worked as leisure (other input factors) become(s) relatively more attractive (substitution effect). In response to an increase in average SSC rates, employees might want to increase their hours worked as the previous income can only be realized by working more (income effect). Two arguments support the assumption of no hours responses, however. First, employees who would have earned more than the post-reform cap in 2001 in the absence of the reform are only exposed to a change in the average SSC rate while their marginal SSC rate is constant. Restricting the treatment group to these employees requires only the exclusion of hours responses due to an income effect. This assumption is much weaker as income effects to taxation are often found to be very small (Gruber and Saez (2002)). Second, as shown with the cross-sectional bunching approach, the drop of the marginal $\mathrm{SSC}$ rate at the cap does not provoke any hours responses (section 4). A robustness check for the East German earnings cap of health insurance in 2000 (the year before the reform) based on the SIAB data set reaches the same conclusion (Appendix B.2). The finding of no behavioural responses to the earnings cap is consistent with the literature 
on taxation which usually finds that labour income of employees in the upper part of the earnings distribution is quite unresponsive to taxation (Blundell and Macurdy (1999), Saez (2003)).

The Treatment Group. All employees with potential earnings above the pre-reform earnings cap in 2001 in the absence of the reform are in theory directly affected by the reform. This is unobserved and the treatment group is, thus, approximated by employees earning more than the cap in the reform year 2001. The classification based on post-reform measures might lead to endogenous compositional changes of treatment and control group due to potential reform effects ${ }^{18}$. For the treatment group consisting of all employees with earnings above the pre-reform cap, however, these can only be driven by hours reactions which are shown to be negligible above ${ }^{19}$. Even full shifting to wages cannot explain a decrease of gross earnings below the lower group threshold, i.e. the pre-reform cap. For the treatment group restricted to employees with earnings above the post-reform cap the additional assumption of downward rigidity of the nominal wage rate is required 20 Employees can only be analysed to a certain earnings level because the data is right-censored. Assuming a homogeneous treatment effect, this would not induce an endogeneity problem because the groups are defined by quantiles of the earnings distribution. When the treatment effect is allowed to be heterogeneous, however, a change in wage dynamics due to the reform might induce a downward bias. In a robustness check I, therefore, define the groups by earnings before the reform (Appendix B.6). This circumvents potential endogeneity problems, but comes at some cost. First, employees who would have decreased their earnings below the pre-reform cap in 2001 anyway are falsely allocated to the treatment group and employees who

${ }^{18}$ A similar endogeneity problem is prominently discussed by Blundell, Duncan and Meghir (1998) who instrument the treatment indicator by cohort and education level. This yields very imprecise estimates in the present setting, however. Individual fixed-effects could be included to control for compositional changes of groups over time in mean regressions. However, as individuals naturally change groups over time by ascending or descending the wage distribution, one would have to carefully control for their earnings levels.

${ }^{19}$ In theory, responses at the extensive margin might have a similar effect. As the analysis is restricted to employees in the upper part of the earnings distribution, participation effects arguably are negligible as well.

${ }^{20}$ This assumption is supported by the fact that the average nominal earnings increase in the treatment group between 2000 and 2001 was almost $5 \%$. As the reform increased SSC by at most $2.8 \%$ of gross earnings, even full shifting to employees could on average be achieved by a positive yearly earnings increase. 
cross the cap in the reform year are falsely allocated to the control group. Second, classifying employees based on earnings before the reform eliminates the possibility to define a sub-group of employees exposed to a change in the average, but not the marginal SSC rate. Third, the right-censoring of earnings is much more problematic in that case (see below). Nevertheless, both approaches yield similar results.

The Control Group. The counterfactual earnings dynamics of the treatment group in the absence of a reform is estimated by East German employees earning less than the pre-reform earnings cap of health insurance. The reasoning is that both groups of employees are likely to be affected similarly by national, regional and sectoral shocks as well as inflation.

By contrast, as both groups by definition differ in earnings ${ }^{21}$, rising income inequality or other changes in the income distribution not related to the reform might induce diverging trends. However, the analysis of the common trends assumption suggests that the deviation of the unconditional relative earnings changes between the two groups is constant over time (section 5.4). Nevertheless, a rich set of individual, regional and firm-level covariates is included in the estimation equation. Another threat to internal validity is that the reform generates incentives for firms to substitute between low- and high-earning workers. This might raise the wage rate for the control group (Lang 2003) violating the stable unit treatment assumption of the difference-in-differences approach. In order to maximise the comparability the control group is restricted by a lower threshold which is defined such that the sample sizes of treatment and control group are roughly equal in 2000 .

Econometric Model. The causal effect of the reform on gross earnings is estimated by equation (4). Following Lang (2003), I employ median regressions in order to avoid the dependence on potential outliers:

$$
\Delta Y_{i s t}=\alpha_{s}+\gamma_{t}+\beta D_{s t}+\delta X_{i s t}+\epsilon_{i s t}
$$

\footnotetext{
${ }^{21}$ Using West German employees as control group would circumvent this issue. East and West German earnings dynamics are not comparable, however (Appendix B.3).

22 The basic specifications are re-estimated by mean regressions (Appendix B.7). As expected, the estimates are less robust although the qualitative results are similar.
} 
$\Delta Y_{i s t}$ states the yearly $\log$ earnings change of individual $i$ in group $s$ (i.e. treatment or control group) from year $t-1$ to $t . \alpha_{s}$ are fixed effects for the treatment and control group, $\gamma_{t}$ are year fixed effects. $D_{s t}$ indicates observations in the treatment group in 2001. $X_{\text {ist }}$ are potentially time-varying covariates on the individual, firm or regional level (Appendix B.5). $\epsilon_{i s t}$ is an error term. The average treatment effect on the treated is estimated by $\beta$ which measures the part of the difference in earnings changes between treatment and control group in 2001, which cannot be explained by the average $e^{23}$ difference in other years (conditional on $X_{i s t}$ ). The main specification includes observations from 1997 to 2001. This can be interpreted as a difference-indifferences approach in first differences with three periods before the reform as control periods. The choice of the period is mainly motivated by the common trends analysis below (section 5.4p. I conduct robustness checks by extending the control years to six pre- and six post-reform periods and get similar results (Appendix B.6).

The focus on individual first differences controls for unobserved heterogeneity in earnings levels. It generates two additional problems, though. First, mean reversion might be an issue as employees in the treatment group are more likely to have a large transitory earnings shock in $t$ compared to control observations. If mean reversion is assumed to be constant over time (exemplarily Gruber and Saez (2002)), it is controlled for by group fixed effects similar to other systematic time-constant differences between the control and treatment group.

The estimation sample is an unbalanced panel. The groups are defined separately for every year based on the position in the wage distribution instead of the actual earnings caps or absolute earnings levels. This prevents compositional changes for example induced by the significant increase of the cap of pension insurance in 2003 or by a potential treatment effect. The treatment (control) group contains employees between the 82.39 (71.23) \% and 93.44 (82.38) \% quantile and therefore roughly ten percent of the overall sample respectively. Employees above the $92.14 \%$ quantile are handled as maximally treated. $6.56 \%$ of my sample is considered to be censored.

Firm and job position changes as well as employments which do not last the whole year are excluded in the basic specification. This isolates earnings changes within an

\footnotetext{
${ }^{23}$ Weighted by the number of observations in the respective years.
} 
existing contract circumventing some potential sources of differential trends. It also makes confounding labour supply responses less likely. A robustness check relaxing this restriction finds that I do not miss part of the story there (Appendix B.6).

\subsection{Results}

Descriptive Evidence. The treatment and control group are reasonably similar with respect to the mean values of some key characteristics (table 2). The existing differences are as expected considering the systematic difference in earnings. Treated employees are rather male, higher educated and slightly older. Whether these or other differences induce a differential trend of the outcome variable, can be seen by depicting the evolution of average relative yearly changes in (nominal) gross earnings for the treatment and control group graphically (figure 4). From 1997, these vary around four percent every year with earnings changes being slightly higher in the treatment group. The trends, however, are almost parallel, both before and after the reform. Although it is not a formal test, this suggests that the control group provides a good approximation of the counterfactual outcome of the treatment group. Changes in earnings are considerably higher before 1997 which might still be driven by the reunification of Germany. The basic specification, therefore, only exploits information from 1997 to 2001. In the year of the reform the average earnings change increased similarly in both groups suggesting that earnings did not react to the increase of the earnings cap for SSC. There are also no hints for anticipation or lagged effects.

Difference-in-Differences Estimations. The upper panel of table 3 reports the results of estimating equation (4) by median regressions. The highlighted row contains the estimates of $\beta$, the average treatment effect on the treated. Coefficients of all included covariates (exemplarily for the specification of column (2)) are documented in Appendix B.5.

Columns (1) to (4) pertain to yearly earnings changes whereof columns (1) and (2) ((3) and (4)) report results based on a treatment group including employees with earnings above the pre-reform (post-reform) cap. The median change in gross earnings is lower for control observations than for observations in both treatment groups (see also figure 
Table 2: Sample size and characteristics by treatment and control group in 2001

\begin{tabular}{|c|c|c|c|c|c|c|c|}
\hline & treat & control & & & treat & control & \\
\hline $\mathrm{N}$ & 4,296 & 4,513 & & & 4,296 & 4,513 & \\
\hline variable & \multicolumn{2}{|c|}{ mean } & $\mathrm{p}$ & variable & \multicolumn{2}{|c|}{ mean } & $\mathrm{p}$ \\
\hline Female & 0.46 & 0.52 & 0.00 & Unemp. Rate & 13.90 & 13.86 & 0.59 \\
\hline Age & 44.51 & 43.41 & 0.00 & Yearly Earnings & 37197 & 30630 & 0.00 \\
\hline Tenure & 6.18 & 6.13 & 0.38 & Industry Sector & & & \\
\hline Experience & 8.77 & 8.69 & 0.08 & Agriculture & 0.01 & 0.01 & 0.33 \\
\hline Education & & & & Mining & 0.01 & 0.01 & 0.09 \\
\hline Intermediate & 0.00 & 0.01 & 0.00 & Manufact. & 0.17 & 0.18 & 0.98 \\
\hline Voc. training & 0.51 & 0.73 & 0.00 & Energy/Water & 0.04 & 0.04 & 0.16 \\
\hline Grammar & 0.07 & 0.07 & 0.53 & Constr. & 0.04 & 0.05 & 0.05 \\
\hline University & 0.40 & 0.18 & 0.00 & Commerce & 0.06 & 0.06 & 0.63 \\
\hline Missing & 0.01 & 0.01 & 0.03 & Gastronomy & 0.00 & 0.00 & 0.45 \\
\hline State & & & & Transport & 0.05 & 0.09 & 0.00 \\
\hline Brandenburg & 0.17 & 0.18 & 0.11 & Financial & 0.06 & 0.05 & 0.00 \\
\hline Mecklenburg WP & 0.13 & 0.13 & 0.64 & Real Estate & 0.09 & 0.07 & 0.00 \\
\hline Saxony & 0.34 & 0.30 & 0.00 & Public & 0.18 & 0.18 & 0.58 \\
\hline Saxony Anhalt & 0.20 & 0.20 & 0.99 & Education & 0.17 & 0.06 & 0.00 \\
\hline Thuringia & 0.16 & 0.18 & 0.01 & Health & 0.06 & 0.17 & 0.00 \\
\hline Job Position & & & & Misc. Services & 0.05 & 0.04 & 0.09 \\
\hline Untr. worker & 0.01 & 0.04 & 0.00 & Firm characteristics & & & \\
\hline Tr. worker & 0.10 & 0.22 & 0.00 & No. of Employees & 688 & 672 & 0.53 \\
\hline Foreman & 0.03 & 0.03 & 0.70 & Median FT income & 85.8 & 78.3 & 0.00 \\
\hline Clerk & 0.86 & 0.71 & 0.00 & High Union Cov. & 0.42 & 0.30 & 0.00 \\
\hline
\end{tabular}

4). The difference even increases when covariates are included (columns (1) and (3)). The estimate of the treatment effect based on all treated employees is not significantly different from zero without covariates (column (1)). Conditional on covariates (column (2)), it becomes significantly positive but stays very small (0.12 pp.). Taken at face value, the reform, which increased employees' SSC by $0.9 \mathrm{pp}$. on average, induced median earnings to increase by $0.12 \mathrm{pp}$. When the treatment group is restricted to employees earning more than the post-reform cap (columns (3) and (4)) the point estimate becomes slightly more positive if no covariates are included and decreases to virtually zero with covariates. This lack of a substantial reaction of gross earnings implies that (short-term) economic and legal incidence approximately coincide. This implies that neither employers nor employees are able to shift the additional burden. Recall that the unrestricted treatment group experiences a change in the marginal SSC rate while the restricted treatment group does not. Potential hours responses should induce a downward bias to the estimate of the former group (see section 5.3). The difference between those groups is, however, relatively small and not statistically significant. It also goes in the opposite direction. This lends support to the assumption 
Figure 4: Yearly earnings changes in treatment and control group

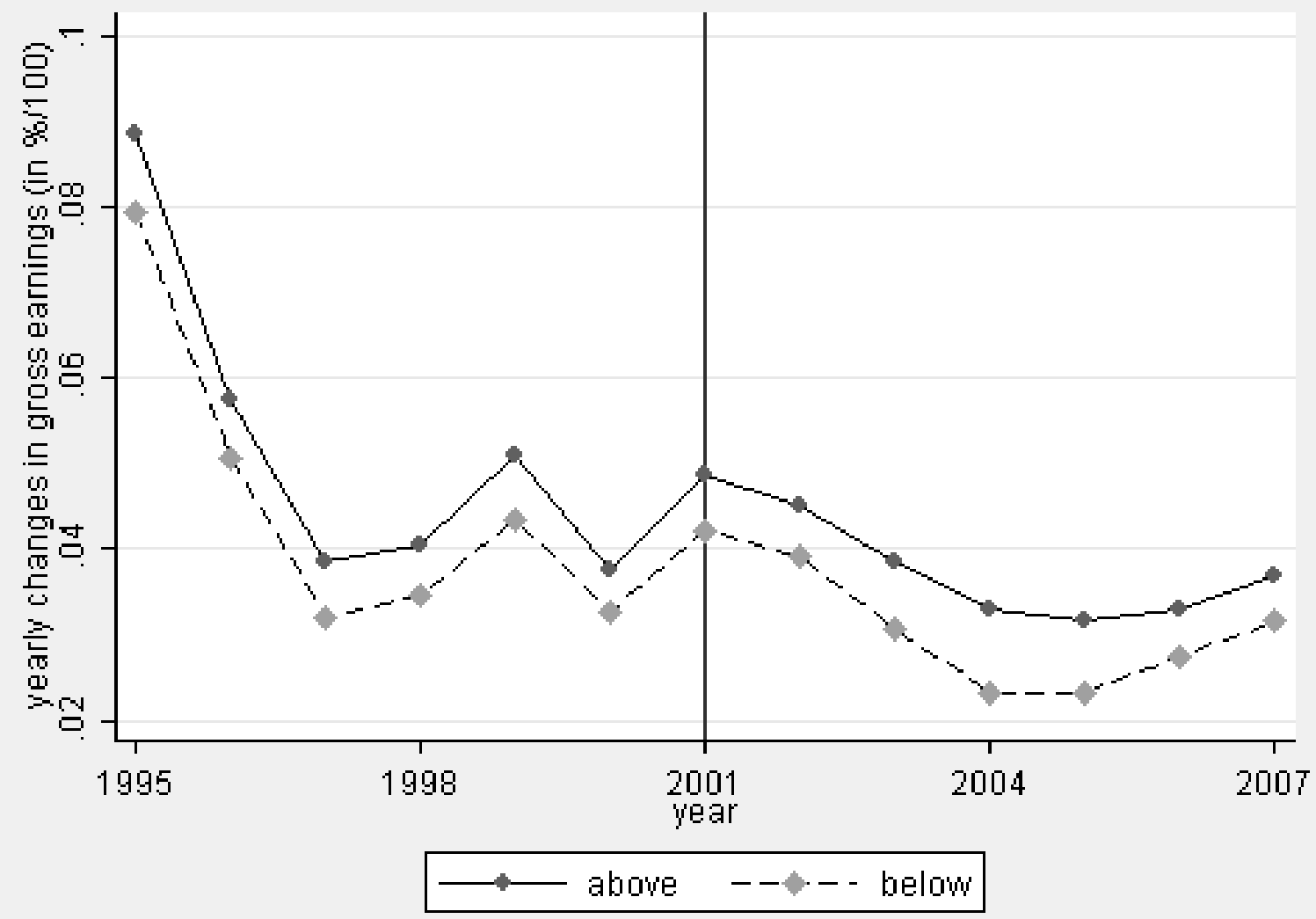

Source: SIAB, own calculations

Notes: Yearly earnings changes in year $t$ are defined as $\ln \left(w_{t} / w_{t-1}\right)$. These values are not comparable to average earnings increases of the whole population. First, I analyse a selective group of employees in the upper part of the earnings distribution and, second, the adjustments described in section 5.2 result in higher earnings increases.

that employment effects at the intensive margin are negligible.

The bootstrapped $95 \%$-confidence interval of column (4) can be used to provide upper bounds of burden shifting implied by the uncertainty ${ }^{24}$ of the estimation. The reform increased SSC by at most $252.8 \%$ of gross earnings or $1.4 \%$ for employees and employers respectively. This increase in SSC is estimated to lead to a decrease (increase) of gross earnings of at most $0.20 \%(0.24 \%) \sqrt{26}$. Thus, the left limit of the confidence interval translates into an upper bound of $14 \%$ of the additional SSC of employers which might be shifted to employees. This implies that substantial shifting to wages can be rejected.

${ }^{24}$ At least the uncertainty induced by measurement error and the finite sample. Uncertainty induced by the common trends assumption as for example discussed in Donald and Lang (2007) is not considered.

${ }^{25}$ Employees in the restricted treatment group are treated homogeneously with respect to the absolute additional liability. As the earnings span within the group is rather small, the relative treatment neither varies much. It can, thus, be directly compared to the impact on the median. By contrast, this calculation would be problematic for the unrestricted treatment group as treatment intensity varies.

${ }^{26}$ This ignores the small bias induced by using the logarithmic change as percentage change. 
Table 3: Reform effects on relative increase of gross earnings, labour costs and net earnings

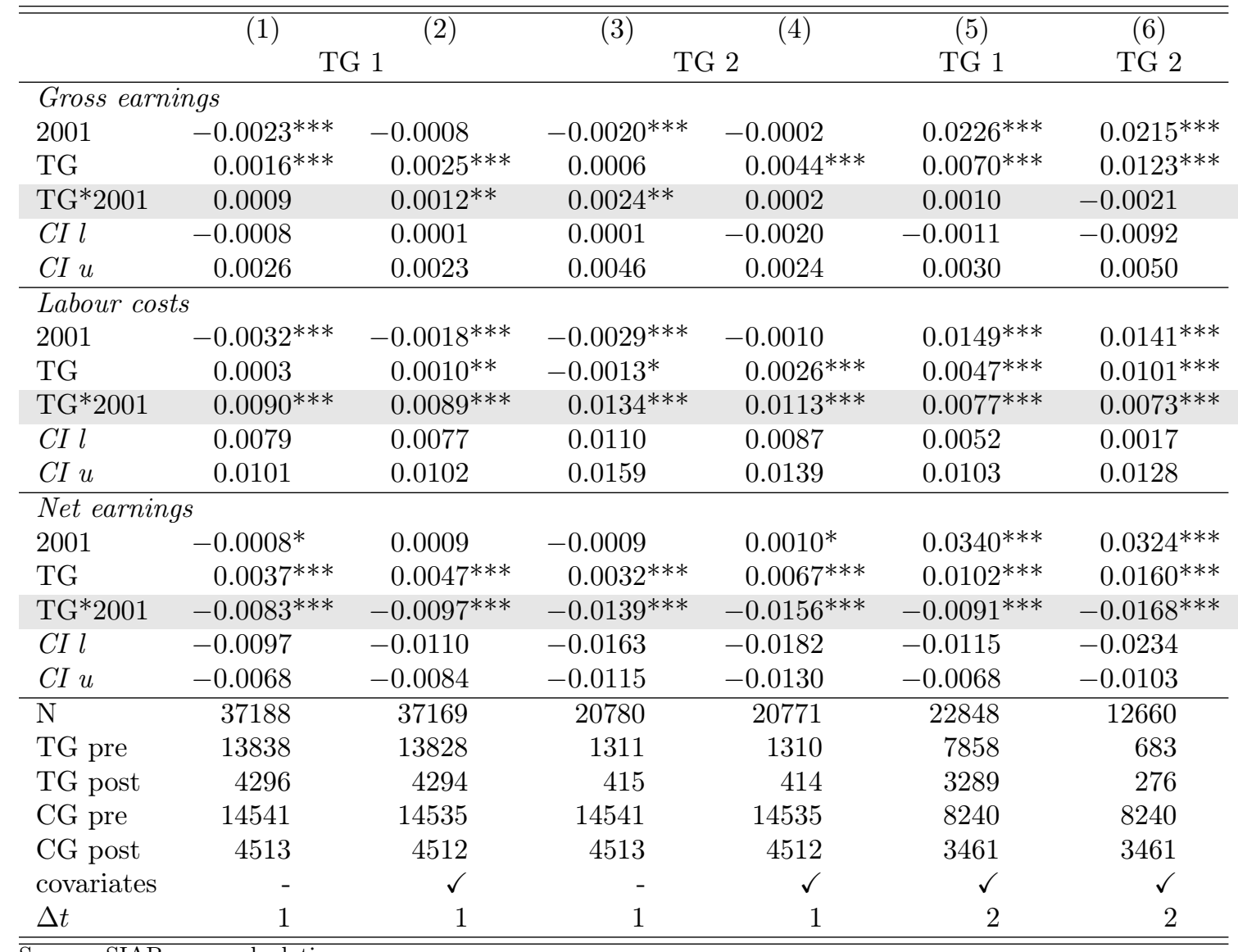

Source: SIAB, own calculations

Notes: $* * * / * * / *$ denote significance on the $1 \%, 5 \%$ and $10 \%$ level respectively. Specifications labelled TG 1 (2) include all employees with earnings above the pre-reform (post-reform) earnings cap in the treatment group. In columns (1)-(4) the outcome variable in $t$ is defined as $\ln \left(w_{t} / w_{t-1}\right)$, in columns (5) and $(6)$ as $\ln \left(w_{t} / w_{t-2}\right)$. Gross earnings are observed, labour costs and net earnings are calculated based on gross earnings. Self-employed, employment spells lasting less than a year as well as job-to-job changes are excluded. The analysed period lasts from 1997 to 2001. Standard errors are bootstrapped by Stata's bsqreg command.

The right limit of the confidence interval would translate into an upper bound of $17 \%$ of the additional SSC liability of employees which might be shifted to employers. Taking into account that roughly one quarter of employees in the treatment group are privately health insured (Appendix B.1) and assuming that health insurance status and earnings are independent (conditional on earnings being above the cap), the upper bound rises to $23 \%$. This implies that considerable shifting to employers can be rejected as well.

The additional burden actually becomes manifest in a statistically significant increase (decrease) in yearly labour costs (net earnings) changes (second and third panel of table 3). Both measures are unobserved and have to be mechanically derived from gross earnings (Appendix B.4). These results underline that the finding of no effect on 
gross earnings does have explanatory power and is not owed to an imprecise estimation. So far, yearly earnings changes have been analysed. Since the reform was announced in December $1999{ }^{27}$, the basic specification captures effects after two years' time. However, reform effects might be lagged even more or take place bit by bit due to frictions (Hamermesh 1993). In order to capture medium-run effects the change in gross earnings between 2000 and 2002 is compared to other non-overlapping two-year changes in the observation period (columns (5) and (6)). For the unrestricted treatment group the point estimate does not change while standard errors increase, arguably due to restricting the sample to employees who have worked in the same company during two successive years. By contrast, the point estimate based on the restricted treatment group decreases sharply but stays insignificant. I find a statistically significant increase (decrease) of labour costs (net earnings) implying that considerable shifting in either direction can still be rejected. The more negative point estimate could be explained by modest lagged behavioural responses. The medium-term results for the restricted treatment group are, however, based on a very small sample size and should not be over-interpreted.

I conduct several robustness checks including the extension of the observation period and allocating employees to treatment and control group based on a pre-reform period (Appendix B.6). I also allow for job-to-job changes and employment periods of less than a year. At last, the analysis is restricted to sectors with low union coverage to ensure that sector-wide collective agreements do not drive the results. The qualitative picture of the results is shown to be reasonably robust. Re-estimating the main specifications by mean regressions comes to similar results (Appendix B.7).

\section{Economic Incidence and Behavioural Responses}

I do not find any behavioural responses to earnings caps for SSC (section 4). Based on the assumption of economic incidence being entirely with employees, I concluded that the labour supply elasticity with respect to SSC is zero or very low. The results of this study (section 5) confirming previous literature for other countries (section 2) suggest

\footnotetext{
${ }^{27}$ Anticipation effects are not expected as possible wage changes can be negotiated in advance. This is
} supported by figure 4 . 
that employers and employees might share the burden of SSC. If this is the case, both, the budget set and the cost function feature a kink at an earnings cap. To see that, imagine an additive cost function of an employer with $y_{j}$ being the gross earnings of employee $j, t_{0 r}\left(t_{1 r}\right)$ the SSC rate actually borne by employers if earnings are below (above) the cap and $C\left(y_{-j}, K\right)$ the costs for other input factors like other workers $\left(y_{-j}\right)$ and capital $(K)$ :

$$
C= \begin{cases}y_{j}\left(1+t_{0 r}\right)+C\left(y_{i}, K\right) & \forall y_{j} \leq \bar{y} \\ \bar{y}\left(1+t_{0 r}\right)+\left(y_{j}-\bar{y}\right)\left(1+t_{1 r}\right)+C\left(y_{-j}, K\right) & \forall y_{j}>\bar{y}\end{cases}
$$

Assuming that employers have a quasi-concave production function $F\left(y_{j}, y_{-j}, K\right)$, the cost function (5) generates the incentive for employers not to contract an employee with earnings close to the kink. The mathematical reasoning is congruent to the discussion of a kink in the budget set (section 4). Intuitively, introducing a kink incentivises employers to increase hours of work for employees with gross earnings higher than $\bar{y}$ in a linear tax system as the marginal costs of an additional hour of work discontinuously drop. Employers would also wish to increase hours of work for employees with gross earnings slightly below $\bar{y}$ in a linear tax system as long as the cost reduction due to the additional lowly taxed hours beyond the kink at least compensates for the additional highly taxed hours up to the kink. A full representation of the firm's problem is beyond the scope of this study. This demonstration, for example, abstracts from the substitutability of production factors. However, even if employees at different positions of the wage distribution are highly substitutable, a gap or dip should emerge since firms would then have the incentive to substitute highly taxed hours below $\bar{y}$ with lowly taxed hours above.

A gap or dip in the earnings distribution around the earnings cap for SSC might, thus, emerge due to behavioural responses of employees, employers or both. As long as economic incidence is not entirely with one side of the market, the method outlined in section 4 cannot separately identify the elasticities of labour supply and demand. It identifies an earnings elasticity which is composed of labour supply and demand responses. This is also true for the usual bunching estimator (Saez 2010) when economic 
incidence of a tax is shared.28

Taking this into account, finding no dips or gaps in the earnings distribution around an earnings cap implies that both, labour supply and labour demand elasticity, have to be zero or very low ${ }^{29}$. Considering the selective sample and the fact that labour demand elasticities are usually found to be lower for skilled employees (Hamermesh 1987), this result is not surprising. An alternative explanation for such low elasticities would be optimization frictions (section 4).

Irrespective of the reason for the low observed elasticities of labour supply and demand, they are consistent with the finding that the economic burden of SSC is neither shifted in large part to employees nor to employers. In a standard competitive partial-equilibrium model of the labour market, economic incidence is determined by the relation of the elasticities of labour supply and demand (Fullerton and Metcalf 2002). If labour demand is considerably more elastic than labour supply the burden of payroll taxes is completely shifted to employees which has been the standard assumption in most analyses of labour supply (Fullerton and Metcalf 2002). However, demand and supply are both found here to be inelastic implying that the burden is equally shared between employees and employers which is empirically confirmed above.

Equal sharing corresponds to legal incidence for the German case. It is, therefore, impossible to determine whether the roughly equal sharing of the burden is driven by the elasticities of labour demand and supply as suggested by the model above. Alternatively, economic could be driven by legal incidence which would disprove the invariance of incidence proposition. Wage rigidities could in the latter case prevent gross wages to adjust in the short run. My analysis of economic incidence is based on changes in SSC over time. A long-run analysis could possibly yield different results. A potential mechanism for the long run might be relative-wage norms which are based on gross wages. Therefore, wage negotiations might be based on gross wages instead of the economically relevant labour costs and net wages (Saez et al. 2012). Laboratory

${ }^{28}$ Allowing economic incidence to be heterogeneous and related to the elasticity the bunching approach does not yield estimates of the average parameters in the population around the cap (Appendix A.4).

${ }^{29} \mathrm{An}$ unlikely alternative explanation is that the labour market consists of two equally frequent types of employee-employer matches where the first (second) is characterised by inelastic employees (employers) and very elastic employers (employees).

${ }^{30}$ The choice of the model is not very restrictive as this central result also follows from most alternative models of the labour market. 
experiments by Weber and Schram (2013) and Kerschbamer and Kirchsteiger (2000) found that subjects have on average a higher after-tax pay-off, when their negotiation partners have to pay the tax. They propose that the legal burden of a tax might induce a moral obligation to bear it.

\section{Conclusion}

This study provides evidence on the impact of SSC on labour earnings of high-skilled employees by exploiting the discontinuities induced by earnings caps for SSC. Two complementary strategies based on two German administrative data sets are used. First, a quasi-experimental approach exploits a significant increase of the East German cap of health insurance in 2001. According to difference-in-differences estimates economic and legal incidence coincide in the short-term. Equivalently, the burden of SSC is shared roughly in equal parts. The main specification rejects that employers are able to shift more than $20 \%$ of the additional legal burden to their employees. Although the average increase of SSC for employees cannot be pinned down exactly, full shifting of their additional legal burden to employers can be rejected as well. As I do not observe hours of work, the reform evaluation does not provide evidence on behavioural responses. It is based on the assumption of no impact on hours of work. I, therefore, translate the cross-sectional bunching approach (Saez (2010) and Chetty et al. (2011)) to upward kinks. Using eight earnings caps between 1998 and 2004 where the drop of the marginal SSC rate varied between 15 and 27 pp., I find that behavioural responses are non-existent or very low. If economic incidence is indeed shared between employers and employees, this suggests that labour supply and demand elasticities both are very low. I argue that both results are consistent in a competitive labour market model where economic incidence is determined by the ratio of labour demand and supply elasticities. If both market sides are similarly inelastic, the economic burden is shared in equal parts.

The combination of non-standard economic incidence and the absence of behavioural responses is in line with previous research (Saez et al. (2012), Skedinger (2014), Bennmarker et al. (2009) and Korkeamäki and Uusitalo (2009)). It contrasts with other 
studies which found that SSC are completely shifted to employees (see for example Gruber (1994) for the US and Gruber (1997) for Chile). The difference might be explained by the institutional settings in the analysed countries. The more centralised wage bargaining in Germany might prevent shifting from employers to employees (Alesina and Perotti 1997).

As in Germany equal sharing corresponds to the legal incidence, it cannot be separated whether this result is driven by the elasticities of labour demand and supply or if legal determines economic incidence. Further, positive economic incidence with employers does not automatically imply that parts of the increase of SSC has a negative impact on firms' profits. Other possible channels like burden shifting to prices or to the entire labour force cannot be captured here.

The result on economic incidence is restricted to a certain year and to East Germany which raises the issue of external validity. The result on behavioural responses is based on several years as well as East and West Germany. The theoretical relationship suggests that the finding on economic incidence can be extrapolated. Moreover, all estimates presented here exploit earnings caps for SSC which only affect employees in the upper part of the earnings distribution. The results are, thus, not necessarily transferable to employees with lower earnings because, for example, the labour demand elasticity might be higher for low-skilled employees (Hamermesh 1987).

The consequences of increasing the earnings cap for SSC is interesting in itself as it constitutes a feasible policy for many countries to increase revenue or to shift the burden to high earners. In the UK, for example, the earnings cap for employers' SSC was abolished in 1985 as were most earnings caps for SSC in France in the 1980s. The finding of no employment responses at the intensive margin implies that the efficiency loss of an increase of an earnings cap seems to be negligible. The results on incidence show that employees and employers would share the increased burden. 


\section{References}

Alesina, Alberto and Roberto Perotti, "The Welfare State and Competitiveness," The American Economic Review, December 1997, 87 (5), 921-939.

Anderson, Patricia M. and Bruce D. Meyer, "The effects of the unemployment insurance payroll tax on wages, employment, claims and denials," Journal of Public Economics, October 2000, 78 (1-2), 81-106.

Baicker, Katherine and Amitabh Chandra, "The Labor Market Effects of Rising Health Insurance Premiums," Journal of Labor Economics, July 2006, 24 (3), 609634.

Bell, Brian, Jerry Jones, and Jonathan Thomas, "Estimating the impact of changes in employers' National Insurance Contribution on wages, prices and employment," Bank of England Quarterly Bulletin 2002.

Bennmarker, Helge, Erik Mellander, and Björn Öckert, "Do regional payroll tax reductions boost employment?," Labour Economics, October 2009, 16 (5), 480 $-489$.

Blundell, Richard, Alan Duncan, and Costas Meghir, "Estimating Labor Supply Responses Using Tax Reforms," Econometrica, July 1998, 66 (4), 827-862.

and Thomas Macurdy, "Labor supply: A review of alternative approaches," in O. Ashenfelter and D. Card, eds., O. Ashenfelter and D. Card, eds., Vol. 3 of Handbook of Labor Economics 1999, chapter 27, pp. 1559-1695.

Büttner, Thomas and Susanne Rässler, "Multiple imputation of right-censored wages in the German IAB Employment Sample considering heteroscedasticity," IAB Discussion Paper 200844, Institute for Employment Research (IAB), Nuremberg December 2008.

Burtless, Gary and Jerry A Hausman, "The Effect of Taxation on Labor Supply: Evaluating the Gary Negative Income Tax Experiments," Journal of Political Economy, December 1978, 86 (6), 1103-30. 
Chetty, Raj, John N. Friedman, Tore Olsen, and Luigi Pistaferri, "Adjustment Costs, Firm Responses, and Micro vs. Macro Labor Supply Elasticities: Evidence from Danish Tax Records," The Quarterly Journal of Economics, 2011, 126 (2), 749-804.

Daveri, Francesco and Guido Tabellini, "Unemployment, growth and taxation in industrial countries," Economic Policy, April 2000, 15 (30), 47-104.

Donald, Stephen G. and Kevin Lang, "Inference with Difference-in-Differences and Other Panel Data," The Review of Economics and Statistics, May 2007, 89 (2), $221-233$.

Dorner, Matthias, Marion König, and Stefan Seth, "Stichprobe der Integrierten Arbeitsmarktbiografien. Regionalfile 1975-2008 (SIAB-R 7508)," Documentation on Labour Market Data, Institute for Employment Research (IAB), Nuremberg 2011.

Fitzenberger, Bernd, Aderonke Osikominu, and Robert Völter, "Imputation Rules to Improve the Education Variable in the IAB Employment Subsample," Schmollers Jahrbuch: Journal of Applied Social Science Studies, 2006, 126 (3), 405-436.

Fullerton, Don and Gilbert E. Metcalf, "Tax incidence," in A. J. Auerbach and M. Feldstein, eds., A. J. Auerbach and M. Feldstein, eds., Vol. 4 of Handbook of Public Economics, Elsevier, 2002, chapter 26, pp. 1787-1872.

Grabka, Markus, "Alternative Finanzierungsmodelle einer sozialen Krankenversicherung in Deutschland - Methodische Grundlagen und exemplarische Durchführung einer Mikrosimulationsstudie.," Dissertation, Technical University Berlin 2004.

Gruber, Jon and Emmanuel Saez, "The elasticity of taxable income: evidence and implications," Journal of Public Economics, April 2002, 84 (1), 1-32.

Gruber, Jonathan, "The Incidence of Mandated Maternity Benefits," American Economic Review, 1994, 84 (3), 622-41. 
_ _ "The Incidence of Payroll Taxation: Evidence from Chile," Journal of Labor Economics, July 1997, 15 (3), 72-101.

Hamermesh, Daniel, "The demand for labor in the long run," in O. Ashenfelter and R. Layard, eds., Handbook of Labor Economics, 1 ed., Vol. 1, Elsevier, 1987, chapter 08, pp. 429-471.

Hamermesh, Daniel S., "New Estimates of the Incidence of the Payroll Tax," Southern Economic Journal, 1979, 45 (4), 1208-1219.

— _ Labor Demand, Princeton University Press, Princeton, 1993.

Hans-Boeckler-Stiftung, "WSI-Tarifarchiv," 2015. http://www.boeckler.de/index_wsi_tarifarchiv.htm ; accessed 2015.

Holmlund, Bertil, "Payroll Taxes and Wage Inflation: The Swedish Experience," Scandinavian Journal of Economics, 1983, 85 (1), 1-15.

Keane, Michael P., "Labor Supply and Taxes: A Survey," Journal of Economic Literature, December 2011, 49 (4), 961-1075.

Kerschbamer, Rudolf and Georg Kirchsteiger, "Theoretically robust but empirically invalid? An experimental investigation into tax equivalence," Economic Theory, 2000, 16 (3), 719-734.

Korkeamäki, Ossi and Roope Uusitalo, "Employment and wage effects of a payrolltax cut-evidence from a regional experiment," International Tax and Public Finance, December 2009, 16 (6), 753-772.

Lang, Kevin, "The Effect of the Payroll Tax on Earnings: A Test of Competing Models of Wage Determination," NBER Working Papers 9537, National Bureau of Economic Research, Inc March 2003.

Liang, Xiaoli, Jeffrey Kubik, and Gary Engelhardt, "The Incidence of the Social Security Payroll Tax: Evidence from the 1977 Amendments to the Social Security Act," Technical Report 2004. 
Liebman, Jeffrey and Emmanuel Saez, "Earnings Responses to Increases in Payroll Taxes," Technical Report 2006.

Meghir, Costas and David Phillips, "Labour Supply and Taxes," in "Dimensions of Tax Design: the Mirrlees Review," Oxford University Press, 2010.

Melguizo, Angel and Jose Gonzalez-Paramo, "Who bears labour taxes and social contributions? A meta-analysis approach," SERIEs, 2013, 4 (3), 247-271.

Neubig, Thomas, "The Social Security Payroll Tax Effect on Wage Growth," Proceedings of the National Tax Association, 1981, pp. 196-201.

OECD, "OECD Employment Output: Employer Versus Employee Taxation: The Impact On Employment," Technical Report, OECD 1990.

_ _ "The OECD Jobs Study Evidence and Explanations - Part II: The Adjustment Potential of the Labour Market," 1994.

_ _ , "OECD revenue statistics," 2015. https://stats.oecd.org/Index.aspx?DataSetCode=REV; accessed 2015 .

Ooghe, Erwin, Erik Schokkaert, and Jef Flechet, "The Incidence of Social Security Contributions: An Empirical Analysis," Empirica, June 2003, 30 (2), 81-106.

Prescott, Edward C., "Why do Americans work so much more than Europeans?," Quarterly Review, 2004, (Jul), 2-13.

Saez, Emmanuel, "The effect of marginal tax rates on income: a panel study of 'bracket creep'," Journal of Public Economics, 2003, 87, 1231 - 1258. , "Do Taxpayers Bunch at Kink Points?," American Economic Journal: Economic Policy, 2010, 2 (3), 180-212.

, Manos Matsaganis, and Panos Tsakloglou, "Earnings Determination and Taxes: Evidence From a Cohort-Based Payroll Tax Reform in Greece," The Quarterly Journal of Economics, 2012, 127 (1), 493-533. 
Skedinger, Per, "Effects of Payroll Tax Cuts for Young Workers," Nordic Economic Policy Review, 2014, 1, 125-169.

Wagner, Gert G., Joachim R. Frick, and Jürgen Schupp, "The German SocioEconomic Panel Study (SOEP) - Scope, Evolution and Enhancements," Schmollers Jahrbuch : Journal of Applied Social Science Studies / Zeitschrift für Wirtschaftsund Sozialwissenschaften, 2007, 127 (1), 139-169.

Weber, Matthias and Arthur Schram, "The Non-Equivalence of Labor Market Taxes: A Real-Effort Experiment," Tinbergen Institute Discussion Papers 13030/I, Tinbergen Institute February 2013.

Wichert, Laura and Ralf A. Wilke, "Which factors safeguard employment?: an analysis with misclassified German register data," Journal of the Royal Statistical Society: Series A (Statistics in Society), 2012, 175 (1), 135-151. 


\section{A Appendix to Section 4}

\section{A.1 Model with Specified Utility Function}

The theoretical implications in section 4 are derived without specifying a utility function. Following Saez (2010), I show the theoretical relationships here for a quasi-linear and iso-elastic utility function:

$$
U(c, y)=c-\frac{n}{1+1 / e}\left(\frac{y}{n}\right)^{1+1 / e}
$$

$n$ denotes an ability or preference parameter, $c$ consumption, $e$ the homogeneous compensated elasticity of labour supply with respect to the net-of-tax rate and $y$ gross earnings. The quasi-linearity simplifies the analysis by excluding income effects which is unproblematic as the change in the average tax rate is negligible close to the kink. A cap at earnings level $\bar{y}$ above which the marginal tax rate drops from $t_{0}$ to $t_{1}$ generates the piecewise linear non-convex budget set (7) with an upward kink at $\bar{y}$ and $R$ being non-wage income.

$$
c= \begin{cases}\left(1-t_{0}\right) y+R & \forall y \leq \bar{y} \\ \left(1-t_{0}\right) \bar{y}+\left(1-t_{1}\right)(y-\bar{y})+R & \forall y>\bar{y}\end{cases}
$$

To find the global maximum subject to a non-convex budget set, Burtless and Hausman (1978) propose to first calculate the unconstrained maxima assuming a linear tax system with the tax rates $t_{0}$ and $t_{1}$ respectively. These are given by $y_{0}^{*}=n\left(1-t_{0}\right)^{e}$ and $y_{1}^{*}=n\left(1-t_{1}\right)^{e}$. Three cases can be differentiated. If $y_{0}^{*}>\bar{y}$ and $y_{1}^{*}>\bar{y}\left(y_{0}^{*}<\bar{y}\right.$ and $\left.y_{1}^{*}<\bar{y}\right), y_{1}^{*}\left(y_{0}^{*}\right)$ is the global maximum as the individual is always better off on the boundary of the budget set than in the interior. If $y_{0}^{*}<\bar{y}$ and $y_{1}^{*}>\bar{y}$, the global maximum is the earnings level with the higher absolute utility. The determination of absolute utility is necessary, since double tangencies are possible if budget sets are nonconvex. This complicates the analysis in comparison to the discussion of downward kinks in Saez (2010). Equations (8) and (9) state the indirect utility functions for the budget segments below and above $\bar{y}$ using the optimal interior earnings levels and the 
relevant budget constraints.

$$
\begin{gathered}
V^{\text {below }}(n)=\left(1-t_{0}\right) n\left(1-t_{0}\right)^{e}+R-\frac{n}{1+1 / e}\left(\frac{n\left(1-t_{0}\right)^{e}}{n}\right)^{1+1 / e} \\
=n\left(1-t_{0}\right)^{e+1}\left(1-\frac{1}{1+1 / e}\right)+R \\
V^{\text {above }}(n)=n\left(1-t_{1}\right)^{e}-\left(t_{1}\left(n\left(1-t_{1}\right)^{e}-\bar{y}\right)+t_{1} \bar{y}+R\right)-\frac{n}{1+1 / e}\left(\frac{n\left(1-t_{1}\right)^{e}}{n}\right)^{1+1 / e} \\
=n\left(1-t_{1}\right)^{e+1}\left(1-\frac{1}{1+1 / e}\right)-R+\bar{y}\left(t_{1}-t_{0}\right)
\end{gathered}
$$

The difference between these interior maxima is linear in ability $n$ with a strictly negative slope:

$$
V^{\text {below }}(n)-V^{\text {above }}(n)=\left[\left(1-t_{0}\right)^{e+1}-\left(1-t_{1}\right)^{e+1}\right] n\left(1-\frac{1}{1 / e}\right)-\bar{y}\left(t_{1}-t_{0}\right)
$$

Thus, there is a specific ability value $\tilde{n}$ for which it holds that employees are indifferent between an allocation below and above the kink. Employees with higher (lower) abilities prefer the interior solution above (below) the kink. As locating between the earnings level $y_{0}^{*}$ and $y_{1}^{*}$ never is a global optimum, the earnings distribution should feature a gap. Equating the indirect utility functions below and above the kink determines $\tilde{n}$, the ability of the marginal jumper, as $\bar{y}$ multiplied by the factor $a\left(t_{0}, t_{1}, \bar{y}, e\right)$ :

$$
\begin{aligned}
& V^{\text {below }}(n) \stackrel{!}{=} V^{\text {above }}(n) \\
& \Leftrightarrow \quad \tilde{n}=\frac{\bar{y}\left(t_{1}-t_{0}\right)}{(1-1 /(1+1 / e))\left[\left(1-t_{0}\right)^{e+1}-\left(1-t_{1}\right)^{e+1}\right]}=\bar{y} a\left(t_{0}, t_{1}, \bar{y}, e\right)
\end{aligned}
$$

If $e \rightarrow 0, a$ converges to one and no gap arises. For $e>0$ it holds that $0<a<1$ ensuring that $\tilde{n}$ lies to the left of the kink. The marginal jumper's earnings response $\Delta \tilde{y}$ to the decrease in the marginal tax rate at $\bar{y}$ is defined by the jump from the interior solution below the kink to the one above:

$$
\tilde{y}_{0}^{*}+\Delta \tilde{y}=\tilde{n}\left(1-t_{0}\right)^{e}+\Delta \tilde{y}=\tilde{y}_{1}^{*}=\tilde{n}\left(1-t_{1}\right)^{e}
$$


Inserting equation (11) elasticity $e$ can be inferred:

$$
\begin{aligned}
& \frac{\bar{y}\left(t_{1}-t_{0}\right)}{(1-1 /(1+1 / e))\left[\left(1-t_{0}\right)^{e+1}-\left(1-t_{1}\right)^{e+1}\right]}\left(1-t_{0}\right)^{e}+\Delta \tilde{y}= \\
& \frac{\bar{y}\left(t_{1}-t_{0}\right)}{(1-1 /(1+1 / e))\left[\left(1-t_{0}\right)^{e+1}-\left(1-t_{1}\right)^{e+1}\right]}\left(1-t_{1}\right)^{e}
\end{aligned}
$$

While $t_{0}, t_{1}$ and $\bar{y}$ are known by the tax system, the earnings response $\Delta \tilde{y}$ can be estimated by the extent of the observed gap.

\section{A.2 Graphical Evidence}

The empirical analysis of section 4 aims at identifying the existence and extent of a dip around the earnings cap for SSC in the gross earnings distribution. Following Chetty et al. (2011) a counterfactual earnings distribution in the absence of an earnings cap is estimated by equation (3). Polynomials of degree seven are fit to the count data with earnings potentially affected by the dip being excluded from the estimation.

The corresponding plots to the estimated differences between the actual and counterfactual earnings distributions (section 4) are documented here (figures 5 to 8). Dots represent the observed, solid lines the counterfactual earnings distributions. The graphs show that the polynomials fit the data well and support the result that both distributions do not deviate.

\section{A.3 Simulation of Utility Gain}

Chetty et al. (2011) show that behavioural responses could be impeded by frictions as long as the related costs exceed the utility gains. In order to quantify the potential gains I simulate the change in absolute utility generated by moving from the optimal location in the counterfactual situation of a linear tax rate $t_{0}$ to the optimal location in the actual non-linear setting. Simulations are conducted for an individual with an ability such that it would be optimal to locate at the cap in the counterfactual situation. It, therefore, yields an upper bound of the utility gain. The gain for the employer is not considered. Tax rates and earnings caps are chosen according to the law applicable in Germany in 2004. The exercise is carried out for two compensated elasticities of 
Figure 5: Observed and counterfactual distribution around the earnings caps of pension insurance in 2004
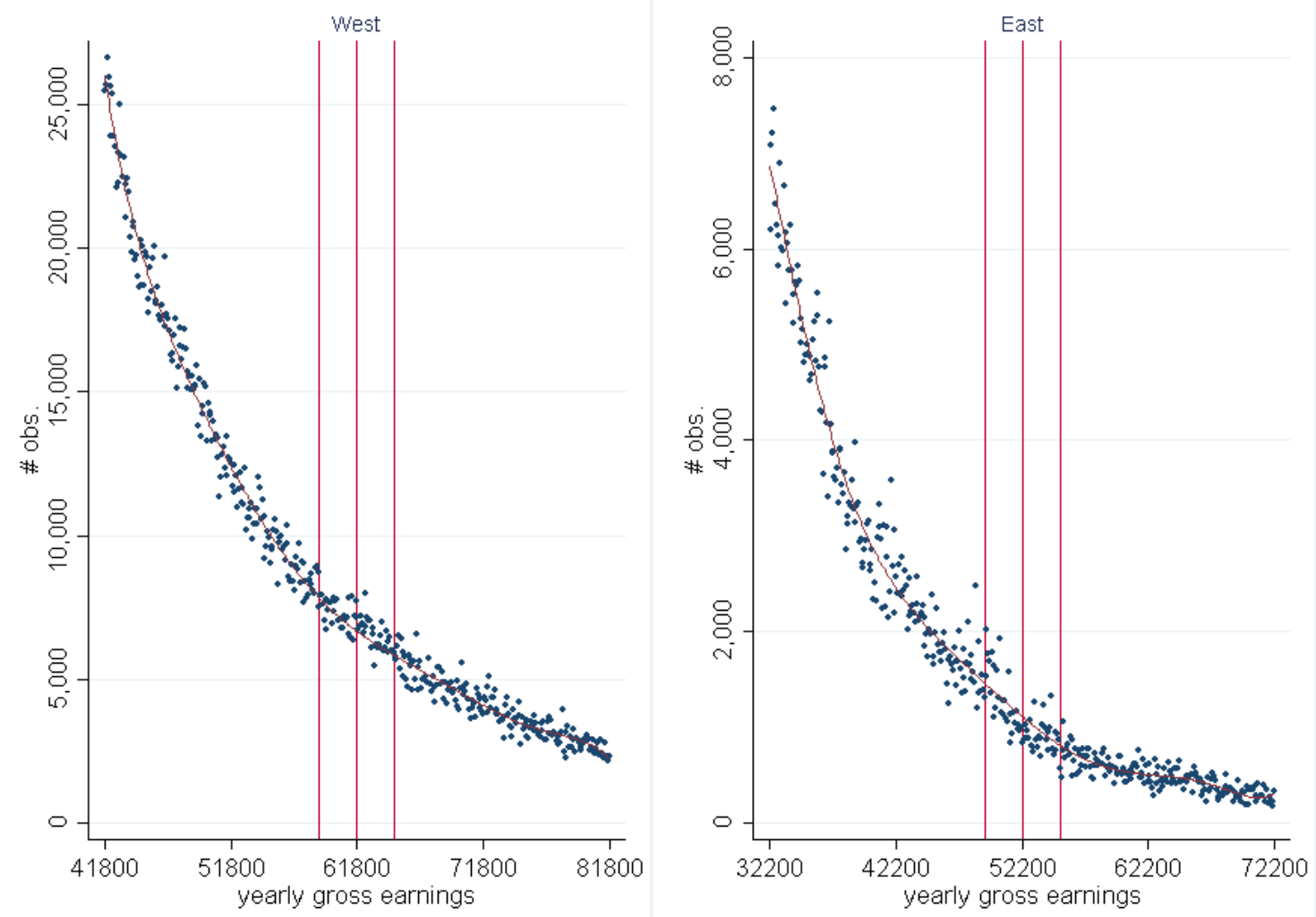

Source: FAST, own calculations

Notes: The dots represent the absolute frequency in earnings bins of size $100 €$. The solid curve is a polynomial of degree seven fit to these frequencies excluding the bins between the first and third vertical reference line. The second reference line represents the earnings cap. $B_{N}(B)$ states the absolute (relative) excess or missing mass, $B_{s} e$ is the correspondig standard error. This graph is generated by a slight modification of the program code provided by Chetty et al. (2011).

labour supply: 0.1 is frequently estimated in static empirical studies; 0.5, alternatively, is quite high in the distribution of estimates (see Keane (2011) for a recent survey). The utility gain, expressed in yearly earnings, ranges from almost $300 €$ for $e=0.5$ at the earnings cap of pension insurance in West Germany to $16 €$ for $e=0.1$ at the earnings cap of health insurance (table 4). This simulation exercise also underlies the choice of the exclusion range which is set to $3000 €$ corresponding approximately to the earnings changes based on $e=0.5$. 
Figure 6: Observed and counterfactual distribution around the earnings cap of health insurance in 2004
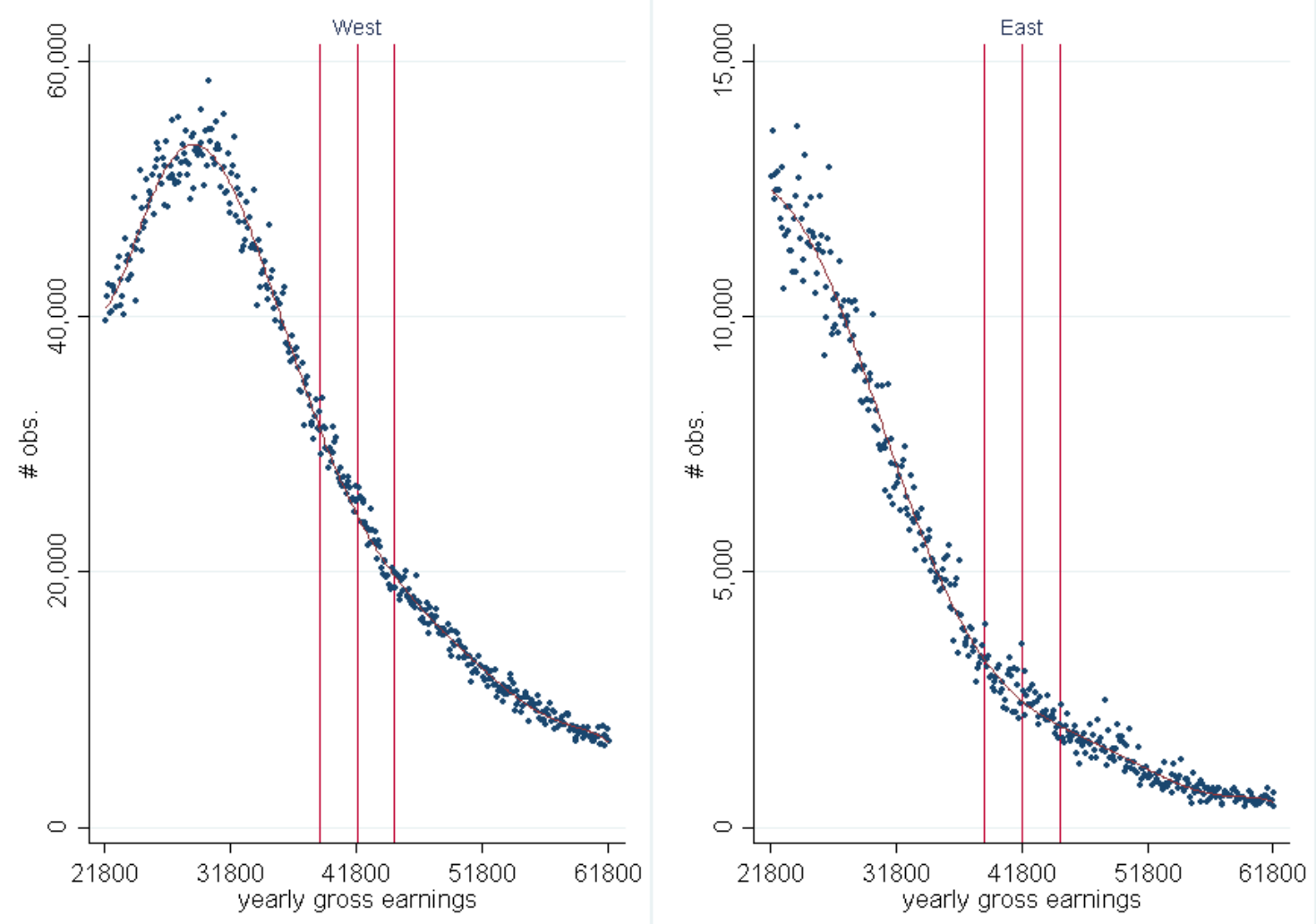

Source: FAST, own calculations

Notes: The dots represent the absolute frequency in earnings bins of size $100 €$. The solid curve is a polynomial of degree seven fit to these frequencies excluding the bins between the first and third vertical reference line. The second reference line represents the earnings cap. $B_{N}(B)$ states the absolute (relative) excess or missing mass, $B_{s} e$ is the correspondig standard error. This graph is generated by a slight modification of the program code provided by Chetty et al. (2011).

\section{A.4 Allowing for heterogeneous economic incidence}

Relaxing the assumption that economic incidence falls entirely to employees and allowing economic incidence to be heterogeneous as well as to be correlated with the elasticity, the bunching estimator (equation (2) above) becomes:

$$
\begin{aligned}
B & =\iiint_{y_{0}}^{y_{0}+\Delta y(e, s)} h_{0}(y, e, s) d y d e d s \\
& \approx \iint d y(e, s) \overline{h_{0}(y, e, s)} d e d s \\
& =E_{e, s}[d y] \overline{h_{0}(y)}
\end{aligned}
$$

$s$ is a parameter that denotes the extent and direction of burden shifting. Equation 
Figure 7: Observed and counterfactual distribution around the earnings caps of pension insurance in 1998
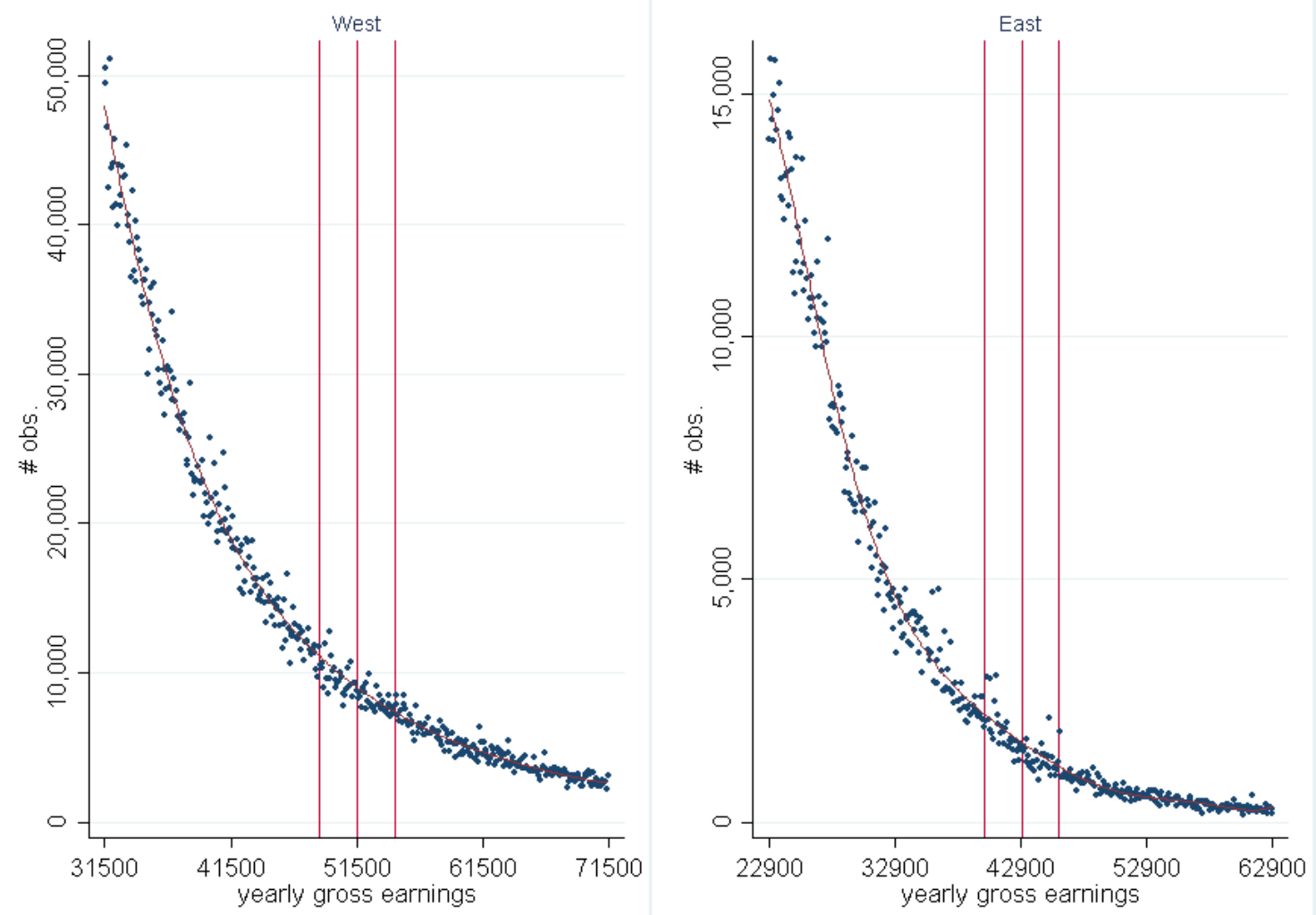

Source: FAST, own calculations

Notes: The dots represent the absolute frequency in earnings bins of size $100 €$. The solid curve is a polynomial of degree seven fit to these frequencies excluding the bins between the first and third vertical reference line. The second reference line represents the earnings cap. $B_{N}(B)$ states the absolute (relative) excess or missing mass, $B_{s} e$ is the correspondig standard error. This graph is generated by a slight modification of the program code provided by Chetty et al. (2011).

(13) implies that the missing or excess mass $B$ does not represent the average earnings response in the population around the cap but an average earnings response weighted by the joint density of incidence and elasticity. However, since I do not find any missing mass (section 4 above) this is not relevant here.

\section{B Appendix to Section 5}

\section{B.1 The German System of Private Health Insurance}

The private health insurance system is a peculiarity within the German health insurance system which has important implications for the quasi-experimental analysis of section 
Figure 8: Observed and counterfactual distribution around the earnings cap of health insurance in 1998
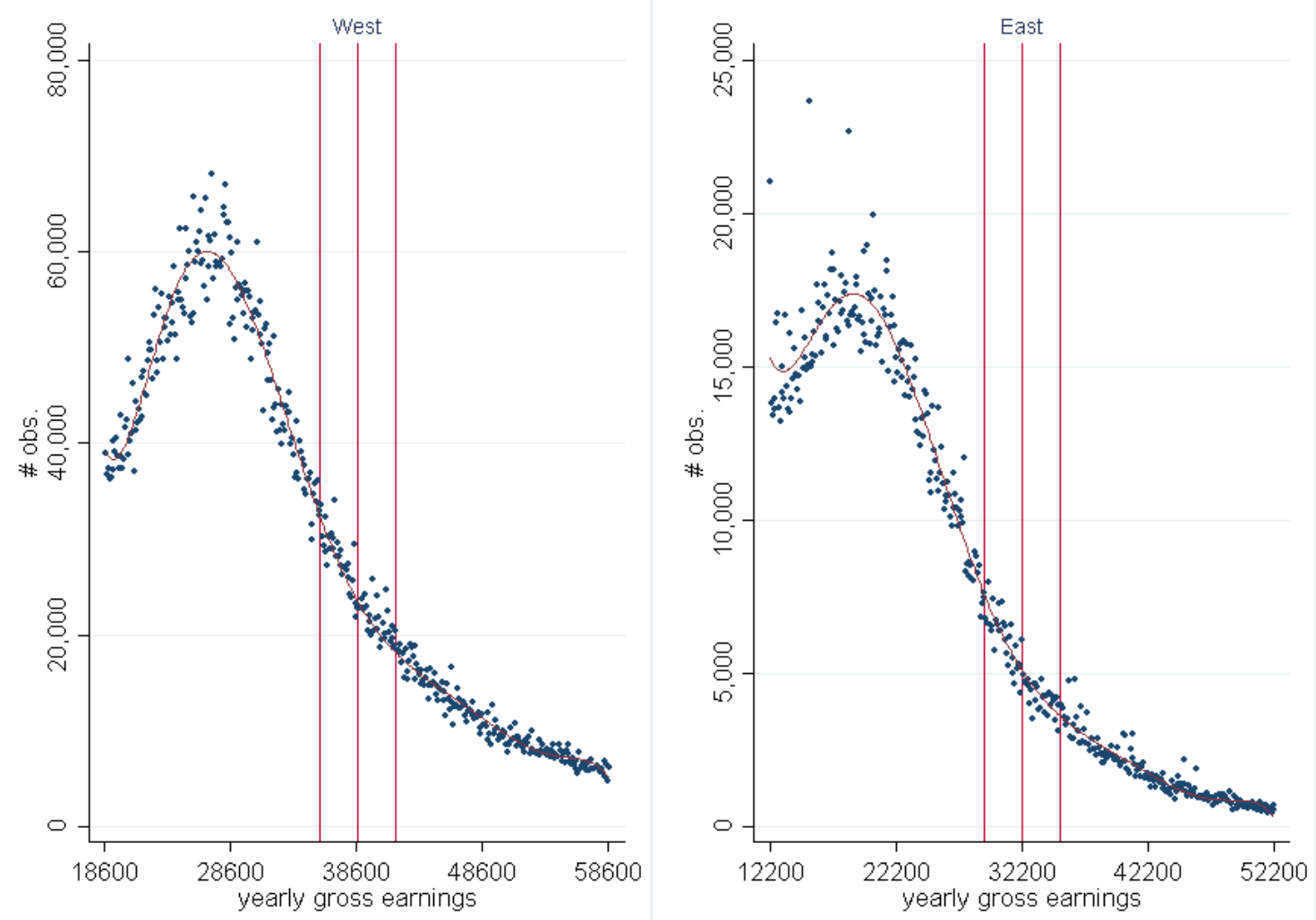

Source: FAST, own calculations

Notes: The dots represent the absolute frequency in earnings bins of size $100 €$. The solid curve is a polynomial of degree seven fit to these frequencies excluding the bins between the first and third vertical reference line. The second reference line represents the earnings cap. $B_{N}(B)$ states the absolute (relative) excess or missing mass, $B_{s} e$ is the correspondig standard error. This graph is generated by a slight modification of the program code provided by Chetty et al. (2011).

\section{5}

Employees with earnings above the income threshold for compulsory insurance, $\overline{\bar{y}}$, may leave mandatory public and opt for private health insurance. Usually this comes into effect the year after $\overline{\bar{y}}$ was exceeded for the first time and only if it can be anticipated that earnings are constantly above $\overline{\bar{y}}$. At the time of the reform, $\overline{\bar{y}}$ coincided with the earnings cap. Therefore, most treated employees were exempted from compulsory insurance and could have been privately insured before the reform. The employees' contributions to private health insurance do not depend on the wage but on individual characteristics. The cap and its increase are, thus, irrelevant ${ }^{31}$. The employers' share

31 This is only valid with respect to health but not long-term care insurance. The contribution rate to the latter is relatively small, though. 
Table 4: Utility gain of employment response, in $€$

\begin{tabular}{lllllr}
\hline \hline$e$ & $t_{0}$ & $t_{1}$ & $\bar{y}$ & $y^{*}$ & $\Delta U$ \\
0.5 & 0.13 & 0.00 & 61800 & 66257 & 293.03 \\
0.5 & 0.13 & 0.00 & 52200 & 55964 & 247.52 \\
0.5 & 0.21 & 0.13 & 41850 & 43907 & 82.51 \\
0.1 & 0.13 & 0.00 & 61800 & 62667 & 57.51 \\
0.1 & 0.13 & 0.00 & 52200 & 52932 & 48.58 \\
0.1 & 0.21 & 0.13 & 41850 & 42254 & 16.29 \\
\hline \hline
\end{tabular}

Source: own calculations
Notes: $e$ is the assumed elasticity of labour supply. $t_{0}$ and $t_{1}$ are the SSC rates below and above the respective earnings caps $\bar{y} . y^{*}$ is the optimal earnings level and $\Delta U$ states the utility gain from moving from $\bar{y}$ to $y^{*}$. The third and last row replicate the earnings cap of health insurance where $\Delta t=-7.96 p p$. in 2004. The first (second) and fourth (fifth) row replicate the earnings cap of pension insurance in West (East) Germany where $\Delta t=-13 p p .$.

amounts to $50 \%$ of total contributions up to the maximum value of employers' SSC in public health insurance. The reform affects the employers' share similarly in both regimes, only if the employers' share hits this maximum value before and after the reform. This was the case for $72 \%$ of privately insured employees 32 . The 2001 reform also increased $\overline{\bar{y}}$ resulting in sudden compulsory insurance for employees earning between the pre- and post-reform caps. Although an exception rule allowed this group of employees to apply for a permanent exemption from compulsory insurance, most of them switched to public health insurance (table 5). This might have increased or decreased an employee's share depending on the actual contribution rates; the employers' part increased unambiguously ${ }^{33}$.

Privately and publicly insured employees cannot be differentiated within the SIAB data set. Another administrative data set, the employment panel of the Institute for Employment Research (BAP), includes the health insurance status, however, and allows to analyse a group similar to the treatment group in 2000 and 2001. Before the reform roughly one quarter of the treated employees was privately insured ("no contribution", table 5). Another quarter was voluntarily publicly insured ${ }^{34}$. Thus, nearly half of the treated employees were compulsory publicly insured in 2000. They might have exceeded the threshold for the first time or just due to irregular payments. The lion's

${ }^{32}$ This refers to my own calculations based on the socio-economic panel (SOEP). See Wagner, Frick and Schupp (2007) for a detailed description of the data set.

${ }^{33}$ Strictly speaking, a slight decrease is possible because the upper threshold is calculated based on the average contribution rates which differed between health insurance companies in 2001.

${ }^{34}$ However, this declaration is voluntary and it just includes voluntarily publicly insured employees whose employers transfer the contributions directly. If that does not apply employees are coded as privately insured. Hence, the share of privately insured (table 5 represents an upper bound. 
share of employees earning between the pre- and post reform cap did not seem to opt for staying in the private health insurance system such that over $90 \%$ of the treated employees were publicly insured in 2001 (table 5). This means that assuming that everyone is constantly publicly insured is justifiable for the treatment of employers but problematic for employees.

Table 5: Status of health insurance, employees in treatment group

\begin{tabular}{lrr}
\hline \hline Status & 2000 & 2001 \\
\hline no contribution & 25.35 & 9.19 \\
compulsory contribution & 47.64 & 84.99 \\
voluntary contribution & 27.04 & 5.82 \\
\hline \hline
\end{tabular}

Source: BAP, own calculations

Notes: "no contribution": privately insured employees; "compulsory cont.": employees who are in the compulsory public health insurance system; "voluntary cont.": voluntarily publicly insured employees. The latter declaration is voluntary and it just includes employees whose employers transfer the contributions directly. If that does not apply employees are coded as "no contribution".

\section{B.2 Bunching Analysis of the Earnings Distribution in 2000}

As working hours and hourly wage are not observed in the SIAB, identification of economic incidence requires the assumption that the increase in the earnings cap of health insurance did not provoke hours reactions (Saez et al. 2012). In order to support this assumption, I repeat the bunching analysis of behavioural responses to the earnings cap (section 4) for 2000, the year before the evaluated reform. The analysis is based on the sample of employees included in the reform evaluation. There does not seem to be a deviation between the empirical and counterfactual earnings distribution around the cap (figure 9); the point estimate is not statistically significant. This implies that the drop of the marginal SSC rate at the cap does not evoke hours reactions.

\section{B.3 Testing the Validity of an Alternative Control Group}

The main disadvantage of the control group used in section 5 is that treated and control observations differ with respect to their position in the earnings distribution. This restriction could be relaxed by using a control group consisting of West German employ- 
Figure 9: Observed and counterfactual distribution around the earnings cap of health insurance in 2000

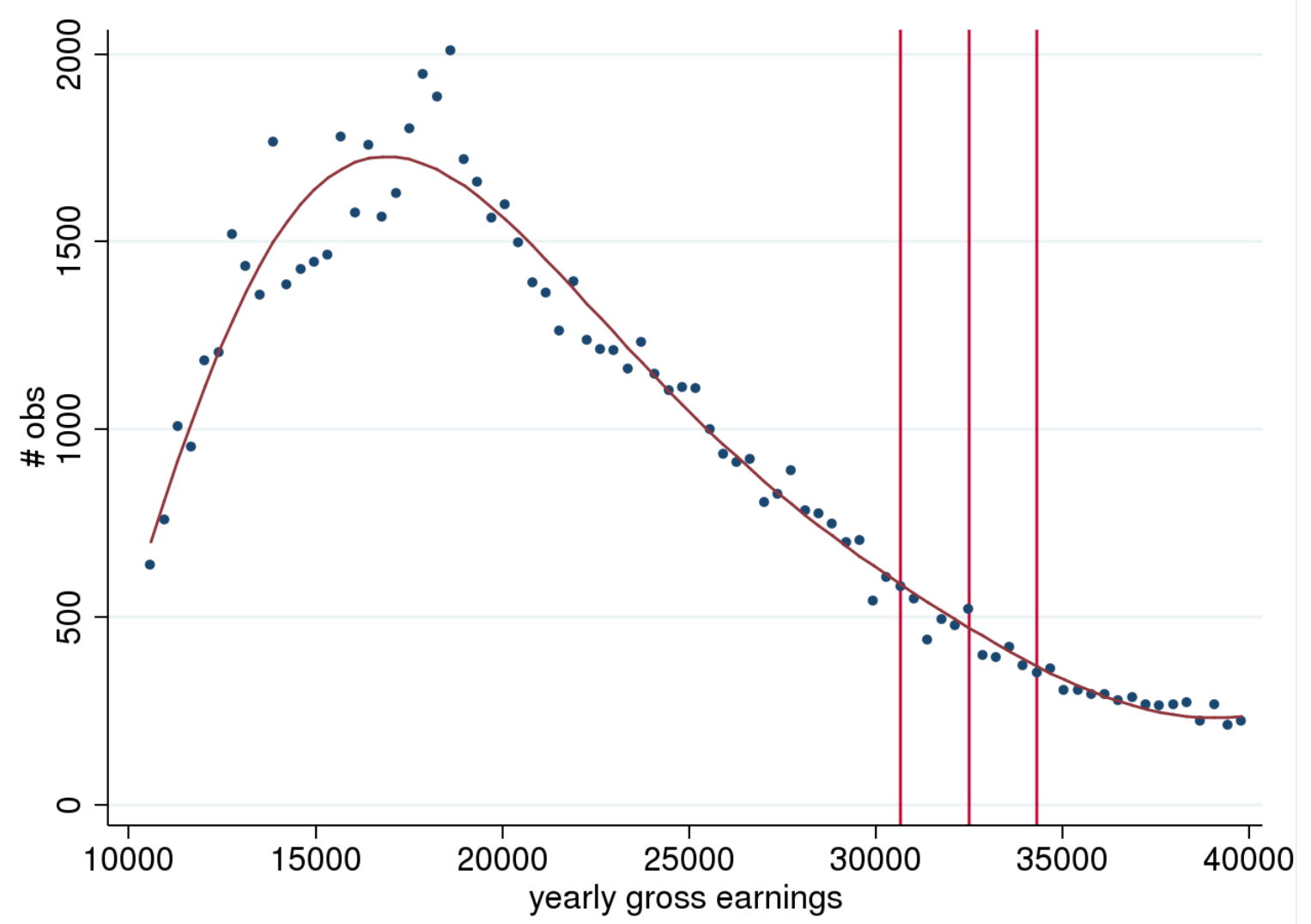

Source: SIAB, own calculations

Notes: The dots represent the absolute frequency in daily earnings bins of size $1 €$. The solid curve is a polynomial of degree 7 fit to these frequencies excluding the bins between the first and third vertical reference line. The second reference line represents the earnings cap.

ees. They are not affected by the reform as their earnings cap increased only slightly by $1.2 \%$ in 2001. On the other hand the cap is much higher in East Germany on relative terms. In 2000 it corresponded to $160 \%$ of the median wage in my sample; the value for West Germany was just $135 \%$. Defining the control group based on the position in the earnings distribution is, thus, not feasible. The upper threshold would be too close to the cap of pension insurance above which earnings are censored. Therefore, I use West German employees with earnings above the West German cap as control observations. I plot yearly changes in gross earnings over time for the treatment and the West German control group to compare their trends (figure 10). The earnings change in $t$ is defined as $\ln \left(w_{t} / w_{t-1}\right)$. The curves of both groups are far from parallel implying that the validity of the West German control group is dubious. I, therefore, do not use this control group for the analysis. 
Figure 10: Yearly earnings changes, East vs. West German employees

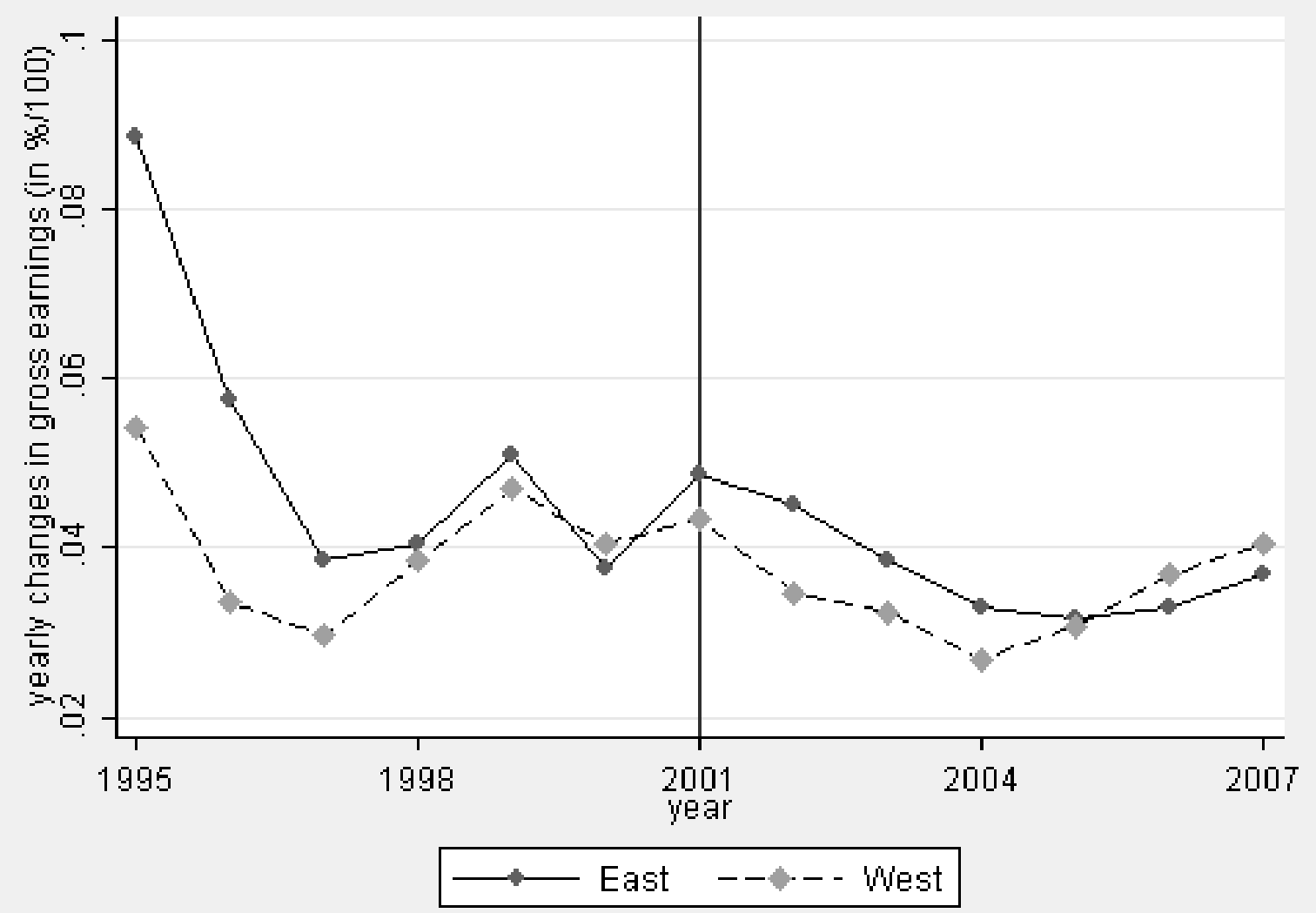

Source: SIAB, own calculations

Notes: Yearly earnings changes in year $t$ are defined as $\ln \left(w_{t} / w_{t-1}\right)$. These values are not comparable to average earnings increases of the whole population. First, I analyse a specific group of rather well earning employees and, second, the adjustments described in section 5.2 result in higher earnings increases.

\section{B.4 Labour Costs and Net Earnings}

It is argued that if the reform had no impact on gross earnings there is a deterministic effect for labour costs $(\mathrm{z})$ and net earnings (c; section 5.3). As I do not observe these quantities they have to be inferred from gross earnings as follows:

$$
\begin{aligned}
& z= \begin{cases}y(1+t)=\frac{n}{1+t * s}(1+t) & \forall y \leq \bar{y} \\
y+\bar{y} t=n-\bar{y} t * s+\bar{y} t & \forall y>\bar{y}\end{cases} \\
& c= \begin{cases}y(1-t)=\frac{n}{1-t * s}(1-t) & \forall y \leq \bar{y} \\
y-\bar{y} t=n-\bar{y} t * s-\bar{y} t & \forall y>\bar{y}\end{cases}
\end{aligned}
$$

Doing so implicitly assumes that everyone is in public health insurance which is not 
true. This bias is much less important for labour costs than for net earnings (Appendix B.1). Therefore, the yearly changes are only plotted for labour costs (figure 11). As for gross earnings the development of control and treatment group is almost parallel. One exception is the year 2001 when labour costs in the treatment group increased much stronger than in the control group suggesting a positive treatment effect. This eye test is supported by the estimation based on labour costs (section 5.4).

Figure 11: Yearly labour cost changes, East German employees above and below the earnings cap for SSC

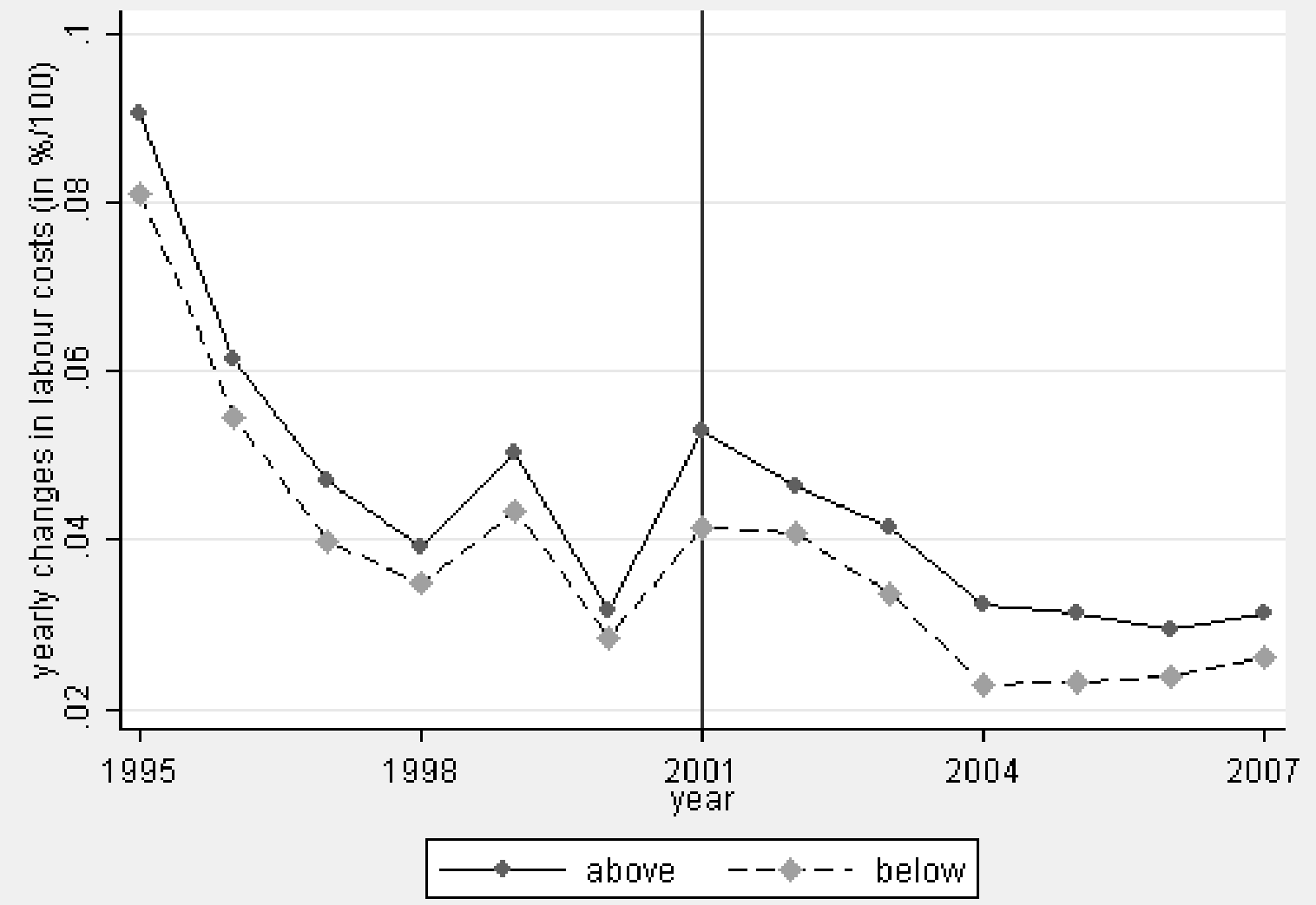

Source: SIAB, own calculations

Notes: Yearly labour cost changes in year $t$ are defined as $\ln \left(z_{t} / z_{t-1}\right)$. The additional fee for childless employees, introduced in 2005, is omitted. The adjustment of SSC which came into effect in July 2005, are considered as of 2006.

\section{B.5 Estimation Table}

The estimation results (table 6) of all covariates refer to the basic specification (section 5.4 . 
Table 6: Marginal Effects

\begin{tabular}{|c|c|}
\hline & $(1)$ \\
\hline 2001 & -0.0008 \\
\hline $\mathrm{TG}$ & $0.0025^{* * *}$ \\
\hline $\mathrm{TG}^{*} 2001$ & $0.0012^{* *}$ \\
\hline Male & $0.0019^{* * *}$ \\
\hline Age & $-0.0043^{* * *}$ \\
\hline $\operatorname{Age}^{2}$ & $0.0000^{* * *}$ \\
\hline Tenure & -0.0003 \\
\hline Tenure $^{2}$ & 0.0000 \\
\hline Experience & -0.0003 \\
\hline Experience $^{2}$ & $0.0000^{* *}$ \\
\hline \multicolumn{2}{|l|}{ Education (ref: Vocational training) } \\
\hline Intermediate school degree or lower & -0.0025 \\
\hline Grammer school degree & $0.0016^{* * *}$ \\
\hline University or college degree & $-0.0009^{* * *}$ \\
\hline Missing & -0.0017 \\
\hline \multicolumn{2}{|l|}{ State (ref: Thuringia) } \\
\hline Brandenburg & $-0.0025^{* * *}$ \\
\hline Mecklenburg WP & $-0.0022^{* * *}$ \\
\hline Saxony & $-0.0015^{* * *}$ \\
\hline Saxony Anhalt & $-0.0018^{* * *}$ \\
\hline \multicolumn{2}{|l|}{ Job position (ref: Trained worker) } \\
\hline Untrained worker & 0.0012 \\
\hline Foreman & $-0.0058^{* * *}$ \\
\hline Clerk & $-0.0046^{* * *}$ \\
\hline \multicolumn{2}{|l|}{ Industry sector WZ1993 (ref: Mining) } \\
\hline Agriculture & $0.0156^{* * *}$ \\
\hline Manufacturing & $0.0178^{* * *}$ \\
\hline Energy/Water & $0.0158^{* * *}$ \\
\hline Construction & -0.0025 \\
\hline Commerce & $0.0136^{* * *}$ \\
\hline Gastronomy & $0.0252^{* * *}$ \\
\hline Transportation & $0.0235^{* * *}$ \\
\hline Financial & $0.0110^{* * *}$ \\
\hline Real Estate & $0.0117^{* * *}$ \\
\hline Public admin & $0.0168^{* * *}$ \\
\hline Education & $0.0129^{* * *}$ \\
\hline Health & $0.0167^{* * *}$ \\
\hline Misc Services & $0.0164^{* * *}$ \\
\hline Industry with high union coverage & $0.0044^{* * *}$ \\
\hline \multicolumn{2}{|l|}{ Firm characteristics } \\
\hline Number of employees & 0.0000 \\
\hline Median daily income of fulltime employee & $0.0001^{* * *}$ \\
\hline Regional unemployment rate & 0.0000 \\
\hline 1998 & $-0.0088^{* * *}$ \\
\hline 2000 & $-0.0138^{* * *}$ \\
\hline Constant & $0.1362^{* * *}$ \\
\hline
\end{tabular}

Source: SIAB, own calculations

Notes: $* * * / * * / *$ denote significance on the $1 \%, 5 \%$ and $10 \%$ level respectively. The estimation is based on the unrestricted treatment group and corresponds to column (2) of table 3 The outcome variable in $t$ is defined as $\ln \left(w_{t} / w_{t-1}\right)$. Self-employed, employment spells lasting less than a year as well as job-to-job changes are excluded. The analysed period lasts from 1997 to 2001. Standard errors are bootstrapped by Stata's bsqreg command. 


\section{B.6 Robustness Checks}

I present the results of alternative specifications which show the robustness of the main findings (section 5).

Alternative Classification of Treatment Group. An alternative treatment group consists of employees earning more than the earnings cap in the initial period of a pair of years (columns (1) and (2) of table 7). This approach generates misspecification as, first, employees who would have earned less than the pre-reform maximum in 2001 anyway are falsely allocated to the treatment group. Second, employees who cross the cap in the reform year are falsely allocated to the control group. On the other hand, this approach is less prone to endogenous compositional changes. The result for yearly changes is almost unchanged. The estimate for two-year changes increases slightly. This suggests that the main specification does not suffer from the positive bias induced by the potential endogeneity discussed in section 5.3 .

Period 1994-2007. The window of observation is extended to six pre-reform and six post-reform years as control observations (table 7, columns (3) and (4)). The point estimates decrease and the significance of the medium-term estimate disappears. In the basic specification I refrain from using post-reform periods as control periods because the reform might have lagged effects. This would violate the stable unit treatment assumption of difference-in-differences estimators as some control observations would be affected by the reform.

Exclusion of sectors with high union coverage. Collective agreements might pose a problem for the identification strategy because the subject of wage negotiations, usually, is a basic wage which is multiplied by fixed factors in order to get wages for different groups. Apart from adjusting these factors it is not possible to differentiate relative wage increases by employees' characteristics. Therefore, employers subject to collective agreements might shift the additional burden of SSC to their entire workforce. This cannot be captured here as the control group would be affected as well. Coverage with respect to collective agreements is rather low in East Germany, however. In 2001, $44 \%$ of all employees were covered by a sector-wide collective aggreement and an 
Table 7: Reform effects on relative increase of gross earnings, labour costs and net earnings - robustness checks 1

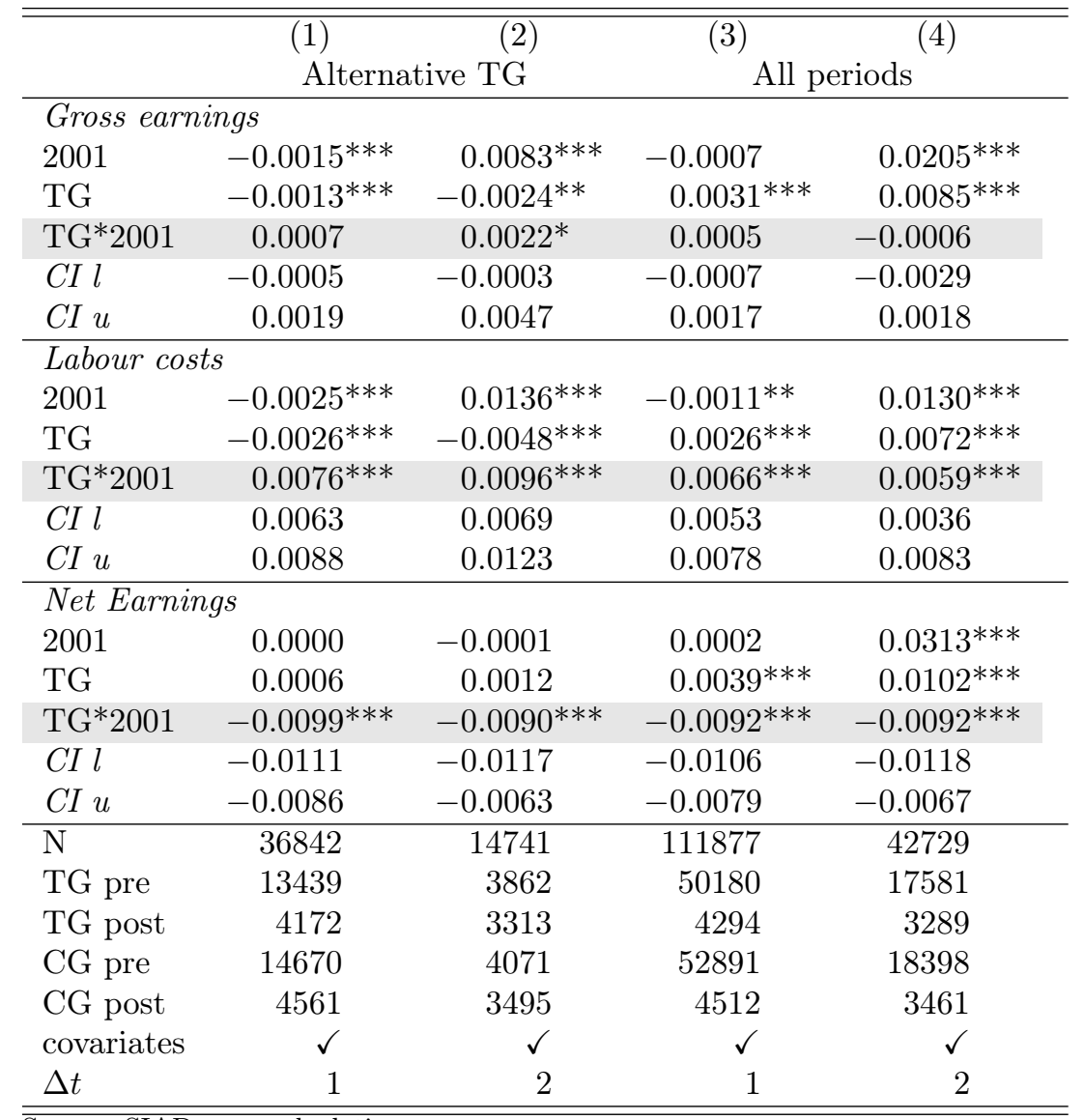

Source: SIAB, own calculations

Notes: $* * * / * * / *$ denote significance on the $1 \%, 5 \%$ and $10 \%$ level respectively. In odd-numbered columns yearly changes are analysed, in even-numbered columns two-year changes. All specifications use the unrestricted treatment group. Gross earnings are observed, labour costs and net earnings are calculated based on gross earnings. Self-employed, employment spells lasting less than a year as well as job-to-job changes are excluded. Individuals are allocated based on the resulting year in columns (3) and (4) and on the initial year in columns (1) and (2). The analysed period lasts from 1997 to 2001 in columns (1) and (2) and from 1994 to 2007 in columns (3) and (4). Standard errors are bootstrapped by Stata's bsqreg command.

additional $12 \%$ by one on the firm-level (Hans-Boeckler-Stiftung 2015). I do not observe, whether a single firm is subject to a collective agreement. Therefore, industry sectors with union coverage rates of more than $50 \%$ are excluded (columns (1) and (2) of table 8). These account for roughly $40 \%$ of treated employees in 2001 whereof many work in the public sector. The point estimate of the reform effect becomes more negative, especially in the medium-term. This might suggest that employers not being subject to a collective agreement are more able to shift the additional burden of SSC. Yet, the estimate is still not statistically significant and the confidence interval still rejects full 
shifting.

Job-to-Job Tranistions and Employment Periods of less than a Year. Earnings changes of job-to-job transitions and employment periods of less than a year are excluded in the basic specification because these observations are more prone to measurement error and labour supply responses (section 5.3). The reform may affect these observations more strongly when it is easier for employees (or their employers) to adjust earnings. The robustness check, therefore, includes earnings changes of job-to-job transitions and employment periods of less than a year (table 8, columns (3) and (4)). The results do not change qualitatively implying that I do not miss part of the story by excluding these observations.

\section{B.7 Mean Regressions}

Following Lang (2003), I employ median regressions to identify the treatment effect in the main specification (section 5). I re-estimate equation (4) by mean regression as an additional robustness check (table 9). The highlighted row contains the estimates of $\beta$, the average treatment effect on the treated. The analysis is based on yearly earnings changes. The treatment group includes employees with earnings above the pre-reform (table 9, columns (1) and (2)) and post-reform cap (table 9, columns (3) and (4)). For none of the specifications a statistically significant treatment effect is found. The point estimate based on the unrestricted treatment group and covariates implies that the reform, which increased employees' SSC by 0.9 pp. on average, induced earnings to increase on average by $0.09 \mathrm{pp}$. (table 9 , column (2)). When the treatment group is restricted to employees earning more than the post-reform cap the point estimate becomes negative (table 9, columns (3) and (4)). Although this difference might be driven by hours responses (section 5.3), it is rather small and not statistically significant. Neither yearly labour costs nor net earnings changes are directly observed but have to be mechanically inferred from gross earnings (Appendix B.4). The significant treatment effects (second and third panel of table 3) imply that the finding of no effect on gross earnings does have explanatory power and is not owed to an imprecise estimation. 
Table 8: Reform effects on relative increase of gross earnings, labour costs and net earnings - robustness checks 2

\begin{tabular}{|c|c|c|c|c|}
\hline & $(1)$ & $(2)$ & $(3)$ & $(4)$ \\
\hline & \multicolumn{2}{|c|}{ Small union coverage } & \multicolumn{2}{|c|}{ Job-to-job } \\
\hline \multicolumn{5}{|c|}{ Gross earnings } \\
\hline 2001 & 0.0006 & $0.0208^{* * *}$ & $0.0031^{* * *}$ & $0.0325^{* * *}$ \\
\hline $\mathrm{TG}$ & $0.0045^{* * *}$ & $0.0119 * * *$ & $0.0052^{* * *}$ & $0.0107^{* * *}$ \\
\hline $\mathrm{TG}^{*} 2001$ & -0.0003 & -0.0026 & 0.0007 & 0.0004 \\
\hline$C I l$ & -0.0027 & -0.0068 & -0.0007 & -0.0022 \\
\hline$C I u$ & 0.0022 & 0.0017 & 0.0021 & 0.0030 \\
\hline \multicolumn{5}{|c|}{ Labour costs } \\
\hline 2001 & -0.0003 & $0.0130 * * *$ & $0.0018^{* * *}$ & $0.0247^{* * *}$ \\
\hline TG & $0.0033^{* * *}$ & $0.0098^{* * *}$ & $0.0037^{* * *}$ & $0.0087^{* * *}$ \\
\hline $\mathrm{TG}^{*} 2001$ & $0.0058^{* * *}$ & $0.0038^{*}$ & $0.0076^{* * *}$ & $0.0064^{* * *}$ \\
\hline$C I l$ & 0.0032 & -0.0003 & 0.0063 & 0.0040 \\
\hline$C I u$ & 0.0084 & 0.0079 & 0.0090 & 0.0088 \\
\hline \multicolumn{5}{|c|}{ Net earnings } \\
\hline 2001 & $0.0019^{*}$ & $0.0325 * * *$ & $0.0049^{* * *}$ & $0.0444^{* * *}$ \\
\hline $\mathrm{TG}$ & $0.0065^{* * *}$ & $0.0146^{* * *}$ & $0.0077^{* * *}$ & $0.0143^{* * *}$ \\
\hline $\mathrm{TG}^{*} 2001$ & $-0.0102^{* * *}$ & $-0.0112^{* * *}$ & $-0.0105^{* * *}$ & $-0.0103^{* * *}$ \\
\hline$C I l$ & -0.0128 & -0.0152 & -0.0119 & -0.0128 \\
\hline$C I u$ & -0.0076 & -0.0073 & -0.0091 & -0.0077 \\
\hline $\mathrm{N}$ & 23895 & 14509 & 53375 & 37300 \\
\hline TG pre & 8034 & 4460 & 20419 & 12903 \\
\hline TG post & 2506 & 1902 & 6410 & 5768 \\
\hline CG pre & 10206 & 5739 & 20189 & 12783 \\
\hline CG post & 3149 & 2408 & 6357 & 5846 \\
\hline covariates & $\checkmark$ & $\checkmark$ & $\checkmark$ & $\checkmark$ \\
\hline$\Delta t$ & 1 & 2 & 1 & 2 \\
\hline
\end{tabular}

Source: SIAB, own calculations

Notes: $* * * * * / *$ denote significance on the $1 \%, 5 \%$ and $10 \%$ level respectively. In odd-numbered columns yearly changes are analysed, in even-numbered columns two-year changes. All specifications use the unrestricted treatment group and allocate individuals based on the resulting year. The analysed period lasts from 1997 to 2001. Gross earnings are observed, labour costs and net earnings are calculated based on gross earnings. Self-employed are excluded. Columns (1) and

(2) additionally excludes job-to-job changes and employment spells lasting less than a year. Columns (3) and (4) exclude all individuals employed in a sector with union coverage rates of more than $50 \%$. Standard errors are bootstrapped by Stata's bsqreg command. 
Table 9: Reform effects on relative increase of gross earnings, labour costs and net earnings - mean regressions

\begin{tabular}{|c|c|c|c|c|c|c|}
\hline \multirow{3}{*}{ 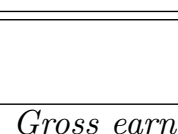 } & \multirow{2}{*}{\multicolumn{2}{|c|}{$(1)$}} & \multirow[t]{2}{*}{$(3)$} & \multirow[t]{2}{*}{ (4) } & \multirow{2}{*}{$\begin{array}{c}(5) \\
\text { TG } 1\end{array}$} & \multirow{2}{*}{$\begin{array}{c}(6) \\
\text { TG } 2\end{array}$} \\
\hline & & & & & & \\
\hline & $n g s$ & & & & & \\
\hline 2001 & $-0.0024^{* *}$ & $0.0042^{* * *}$ & $-0.0023^{*}$ & $0.0043^{* * *}$ & $0.0344^{* * *}$ & $0.0330 * * *$ \\
\hline $\mathrm{TG}$ & $0.0059^{* * *}$ & $0.0107^{* * *}$ & $0.0131^{* * *}$ & $0.0218^{* * *}$ & $0.0176^{* * *}$ & $0.0326^{* * *}$ \\
\hline $\mathrm{TG}^{*} 2001$ & 0.0007 & 0.0009 & -0.0015 & -0.0016 & -0.0012 & 0.0006 \\
\hline$C I l$ & -0.0024 & -0.0022 & -0.0088 & -0.0086 & -0.0056 & -0.0104 \\
\hline$C I u$ & 0.0038 & 0.0039 & 0.0057 & 0.0055 & 0.0032 & 0.0116 \\
\hline \multicolumn{7}{|c|}{ Labour costs } \\
\hline 2001 & $-0.0033^{* * *}$ & $0.0033^{* *}$ & $-0.0029^{* *}$ & $0.0036^{* *}$ & $0.0269^{* * *}$ & $0.0259^{* * *}$ \\
\hline TG & $0.0045^{* * *}$ & $0.0092^{* * *}$ & $0.0106^{* * *}$ & $0.0192^{* * *}$ & $0.0157^{* * *}$ & $0.0289^{* * *}$ \\
\hline $\mathrm{TG}^{*} 2001$ & $0.0072^{* * *}$ & $0.0074^{* * *}$ & $0.0093^{* *}$ & $0.0093^{* * *}$ & $0.0051^{* *}$ & $0.0102^{*}$ \\
\hline$C I l$ & 0.0042 & 0.0044 & 0.0021 & 0.0023 & 0.0008 & -0.0008 \\
\hline$C I u$ & 0.0103 & 0.0104 & 0.0165 & 0.0163 & 0.0094 & 0.0211 \\
\hline \multicolumn{7}{|c|}{ Net earnings } \\
\hline 2001 & -0.0011 & $0.0057 * * *$ & -0.0013 & $0.0053^{* * *}$ & $0.0458^{* * *}$ & $0.0437^{* * *}$ \\
\hline $\mathrm{TG}$ & $0.0079 * * *$ & $0.0129 * * *$ & $0.0169^{* * *}$ & $0.0257^{* * *}$ & $0.0205^{* * *}$ & $0.0381^{* * *}$ \\
\hline $\mathrm{TG}^{*} 2001$ & $-0.0091^{* * *}$ & $-0.0089 * * *$ & $-0.0177^{* * *}$ & $-0.0178^{* * *}$ & $-0.0106^{* * *}$ & $-0.0136^{* *}$ \\
\hline CI l & -0.0122 & -0.0120 & -0.0250 & -0.0249 & -0.0151 & -0.0248 \\
\hline$C I u$ & -0.0059 & -0.0058 & -0.0104 & -0.0106 & -0.0062 & -0.0025 \\
\hline $\mathrm{N}$ & 37188 & 37169 & 20780 & 20771 & 22848 & 12660 \\
\hline TG pre & 13838 & 13828 & 1311 & 1310 & 7858 & 683 \\
\hline TG post & 4296 & 4294 & 415 & 414 & 3289 & 276 \\
\hline CG pre & 14541 & 14535 & 14541 & 14535 & 8240 & 8240 \\
\hline CG post & 4513 & 4512 & 4513 & 4512 & 3461 & 3461 \\
\hline covariates & - & $\checkmark$ & - & $\checkmark$ & $\checkmark$ & $\checkmark$ \\
\hline$\Delta t$ & 1 & 1 & 1 & 1 & 2 & 2 \\
\hline
\end{tabular}

Source: SIAB, own calculations
Notes: $* * * / * * / *$ denote significance on the $1 \%, 5 \%$ and $10 \%$ level respectively. Specifications labelled TG $1(2)$ include all employees with earnings above the pre-reform (post-reform) earnings cap in the treatment group. In columns (1)-(4) the outcome variable in $t$ is defined as $\ln \left(w_{t} / w_{t-1}\right)$, in columns (5) and (6) as $\ln \left(w_{t} / w_{t-2}\right)$. Gross earnings are observed, labour costs and net earnings are calculated based on gross earnings. Self-employed, employment spells lasting less than a year as well as job-to-job changes are excluded. The analysed period lasts from 1997 to 2001. Standard errors are bootstrapped by Stata's bsqreg command. 